\title{
Recent Applications of Capillary Electrophoresis in the Determination of Active Compounds in Medicinal Plants and Pharmaceutical Formulations
}

\author{
Marcin Gackowski ${ }^{1, *(\mathbb{D}}$, Anna Przybylska ${ }^{1}$, Stefan Kruszewski ${ }^{2}{ }^{(0)}$, Marcin Koba ${ }^{1}(\mathbb{D}$, \\ Katarzyna Mądra-Gackowska ${ }^{3}$ and Artur Bogacz ${ }^{4}$ (D) \\ 1 Department of Toxicology and Bromatology, Faculty of Pharmacy, L. Rydygier Collegium Medicum in \\ Bydgoszcz, Nicolaus Copernicus University in Torun, A. Jurasza 2 Street, PL-85089 Bydgoszcz, Poland; \\ aniacm@cm.umk.pl (A.P.); kobamar@cm.umk.pl (M.K.) \\ 2 Biophysics Department, Faculty of Pharmacy, L. Rydygier Collegium Medicum in Bydgoszcz, Nicolaus \\ Copernicus University in Torun, Jagiellońska 13 Street, PL-85067 Bydgoszcz, Poland; skrusz@cm.umk.pl \\ 3 Department of Geriatrics, Faculty of Health Sciences, L. Rydygier Collegium Medicum in Bydgoszcz, \\ Nicolaus Copernicus University in Torun, Skłodowskiej Curie 9 Street, PL-85094 Bydgoszcz, Poland; \\ katarzyna.madra@cm.umk.pl \\ 4 Department of Otolaryngology and Oncology, Faculty of Medicine, L. Rydygier Collegium Medicum in \\ Bydgoszcz, Nicolaus Copernicus University in Torun, Skłodowskiej Curie 9 Street, \\ PL-85094 Bydgoszcz, Poland; arturbogacz@cm.umk.pl \\ Citation: Gackowski, M.; Przybylska,
}

A.; Kruszewski, S.; Koba, M.;

Mądra-Gackowska, K.; Bogacz, A.

Recent Applications of Capillary

Electrophoresis in the Determination of Active Compounds in Medicinal

Plants and Pharmaceutical

Formulations. Molecules 2021, 26,

4141. https://doi.org/10.3390/

molecules26144141

Academic Editors:

Franciszek Główka,

Marta Karaźniewicz-Łada,

François Couderc and

Roberto Mandrioli

Received: 27 April 2021

Accepted: 5 July 2021

Published: 7 July 2021

Publisher's Note: MDPI stays neutral with regard to jurisdictional claims in published maps and institutional affiliations.

Copyright: () 2021 by the authors. Licensee MDPI, Basel, Switzerland.

This article is an open access article distributed under the terms and conditions of the Creative Commons Attribution (CC BY) license (https:// creativecommons.org/licenses/by/ $4.0 /)$.

\begin{abstract}
The present review summarizes scientific reports from between 2010 and 2019 on the use of capillary electrophoresis to quantify active constituents (i.e., phenolic compounds, coumarins, protoberberines, curcuminoids, iridoid glycosides, alkaloids, triterpene acids) in medicinal plants and herbal formulations. The present literature review is founded on PRISMA guidelines and selection criteria were formulated on the basis of PICOS (Population, Intervention, Comparison, Outcome, Study type). The scrutiny reveals capillary electrophoresis with ultraviolet detection as the most frequently used capillary electromigration technique for the selective separation and quantification of bioactive compounds. For the purpose of improvement of resolution and sensitivity, other detection methods are used (including mass spectrometry), modifiers to the background electrolyte are introduced and different extraction as well as pre-concentration techniques are employed. In conclusion, capillary electrophoresis is a powerful tool and for given applications it is comparable to high performance liquid chromatography. Short time of execution, high efficiency, versatility in separation modes and low consumption of solvents and sample make capillary electrophoresis an attractive and eco-friendly alternative to more expensive methods for the quality control of drugs or raw plant material without any relevant decrease in sensitivity.
\end{abstract}

Keywords: capillary electrophoresis; herbal drugs; medicinal plants; quality control; quantitative analysis; pharmaceutical analysis

\section{Introduction}

From early times, people recognized plants for their therapeutic properties. Herbal medicine has been used in the management of many ailments for thousands of years and is the oldest method of healthcare in history [1]. Former herbal "drugs" were discovered by trial and error on human subjects; owing to this, the rich tradition of herbalism contains invaluable biomedical information that is continuously being uncovered by contemporary scientists. In contrast, the dynamic progress of drug production in the 20th century was grounded on the isolation of an active substance with a well-defined mechanism of action. Traditional phytochemistry and pharmaceutical chemistry lines led to the development of many safe and effective drugs used in the clinic today for the treatment of, e.g., diabetes, autoimmune diseases, degenerative disorders and cancer. A well-known example 
of herbalism is traditional Chinese medicine (TCM), which has its followers and is still practiced around the world. Moreover, its potency in numerous illnesses is proved by clinical researchers [2,3]. The use of herbal drugs has been gaining public interest and acceptance. On the one hand, due to poverty and limited access to healthcare in developing countries, people use herbal drugs as a first line of treatment. On the other hand, the most important reason for using herbal therapies in the West is that people believe that herbs will help us live healthier lives and are generally safe for consumption. Individuals often use over-the-counter herbal medicines without medical consultation as home remedies and spend billions of dollars on them. The growing market entails not only abuse but also the adulteration of medicinal products, which can lead to serious health consequences [4]. All drugs, whether of a plant or synthetic origin, should meet safety requirements and be effective $[5,6]$. The content of bioactive constituents is one of the key parameters in assessing the quality of a herbal medicine. In terms of adulteration, which is a very common problem that is mainly linked to the lack of officially established regulations by governmental organizations regarding the control of herbal preparations marketed as dietary supplements, more effective ways are needed to improve control at the production and marketing stages [7-9]. In this light, rapid, simple, accurate qualitative and quantitative methods are essential to evaluate whether herbal formulations fulfill pharmacopoeial requirements.

Quality control of herbal medicines is a real challenge for analysts because of the complex matrix and several characteristic compounds which must be identified and quantified. Apart from this, an elaboration of the analytic method must be completed and a validation protocol fulfilled. Thus, sophisticated, laborious techniques should be employed, such as high-performance liquid chromatography (HPLC), gas chromatography (GC), high performance thin layer chromatography (HPTLC) and capillary electrophoresis (CE). Among the abovementioned techniques, HPLC is the most prevalent one. Liquid chromatography with a diode-array detector (DAD) in conjunction with a mass spectrometer (MS) is an efficient measure to analyze both known and unknown compounds in a complex matrix [10]. HPLC is also the most frequently used technique for the determination of active constituents in TCMs [11].

Capillary electrophoresis has been commonly applied in the analysis of food, environmental monitoring, clinical diagnostics and pharmaceutical analysis. The latter application has become increasingly popular in recent years due to its high separation efficiency, minimal consumption of required solvents and its small sample volume, low running cost, reproducibility, and versatility in separation modes, making it an attractive, eco-friendly and powerful tool suitable for drug control purposes. Thus, CE has found its place in official pharmacopoeias and pharmaceutical control regulations [12,13]. What is more, researchers have found many solutions to handle the unwanted phenomenon, that is the limitation of poor concentration sensitivity [14]. Since the early 1980s, after Jorgenson and Lukacs demonstrated that the effectiveness of the electrophoresis may be increased if it took place in open-tubular glass capillaries with a diameter of $\sim 75 \mu \mathrm{m}, \mathrm{CE}$ has developed into a flexible and versatile technique, which make it a very attractive alternative to other chromatographic techniques $[15,16]$.

In CE, analytes are separated in a capillary column with electroosmotic flow (EOF) as the driving force for bulk fluid movement and the action of the electric field. CE requires only simple instrumentation, consisting of a high voltage power supply, two buffer reservoirs, a sample introduction system, a capillary tube, a detector and an output device. See Scheme 1. The capillary is flooded with a solution of background electrolyte (BGE) at a specific $\mathrm{pH}$, which is usually a buffer able to selectively influence the effective mobility. Different capillaries (fused silica or quartz) with internal diameters ranging from 25 to $100 \mu \mathrm{m}$ and a length of 20 to $100 \mathrm{~cm}$ also affect the analysis conditions. Capillaries are placed together with electrodes in reservoirs flooded with the same buffer. In electrophoresis, a mixture of different substances in solution is introduced, usually as a relatively narrow zone, into the separating system, and is induced to move under the influence of an applied 
potential. The basis for the separation of analytes is in the differences in the electrophoretic mobility of ions as a consequence of the variance in the size and shape of charged particles. Under the influence of an applied electric field, the diverse substances migrate at different rates; thus, after some time, the mixture separates into spatially discrete zones of individual substances $[15,17,18]$. The majority of capillaries for CE are fabricated from fused silica with characteristic silalol groups on the surface. Those groups dissociate, forming a negative charge in the inner surface of the capillary, attracting a positive charge from the buffer, and finally leads to the formation of an electric double layer. The dispersed cation layer (and its hydration sphere) adjacent to the silica surface tends to migrate towards the cathode, resulting in concomitant fluid migration through the capillary. Anions and cations are separated by electrophoretic migration and eloctroosmotic flow, while neutral species only coelute with the EOF $[11,15]$. In the terms of expanding sensitivity, introducing different additives such as methanol or acetonitrile is a common phenomenon. Those compounds work by altering viscosity and the polarity of the running buffer, which, in consequence, affects EOF and the electrophoretic mobility of the analyte [15]. As for improvements to the resolution of different compounds, cyclodextrines, for instance, are added to BGE. The use of an appropriate system for the detection of tested substances makes it possible to record the results of the analyses in the form of an electrophoregram [11,18,19].

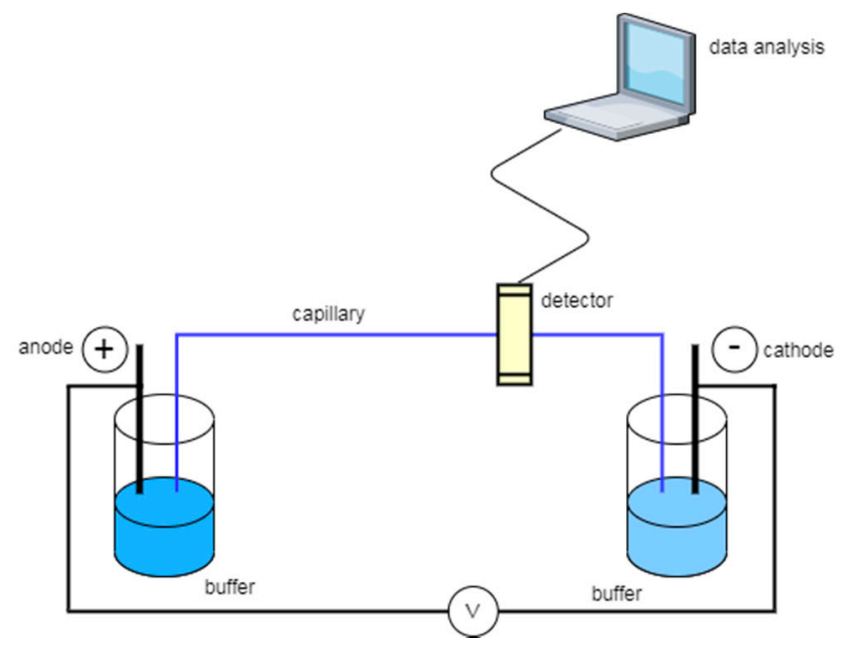

Scheme 1. Capillary electrophoresis system.

Over the last few decades, capillary electrophoresis has attracted attention, because the combination of both chromatographic and electrophoretic mechanisms of migration permits the adoption of different separation formats suited to the chemical structure of the analyzed compounds. The following techniques of $\mathrm{CE}$ are distinguished: capillary zone electrophoresis (CZE), non-aqueous CE (NACE), micellar electrokinetic chromatography (MEKC), capillary electrochromatography (CEC), capillary isotachophoresis (CITP), capillary isoelectric focusing (CIEF), chiral CE (CCE), capillary gel electrophoresis (CGE), and microemulsion electrokinetic capillary chromatography (MEEKC) [17]. To one the bases of charge density, size, hydrophobicity and chirality, analysts can employ CE to different categories of chemicals [15].

The following review summarizes the utilization of $\mathrm{CE}$ for the quantification of active constituents in medicinal plants and commercial herbal products, covering the most important applications between 2010 and 2019 (publications in English only). This scrutiny discusses in detail selected physical and chemical (type of buffer, $\mathrm{pH}$ ) parameters of $\mathrm{CE}$ essential for the selective separation of bioactive constituents. Moreover, there is a greater focus on the influence of different pre-concentration and extraction techniques and additives to the background electrolyte for the improvement of resolution and sensitivity. Special emphasis is placed if the reported methods were applied to real samples (medicinal plants, commercial products) and if they were validated. Apart from reporting the 
current applications of $\mathrm{CE}$, this paper indicates prospects for the further application of this technique.

\section{Results}

\subsection{Literature Analysis}

In the first search in the PubMed and Web of Science database, 682 records potentially meeting the inclusion criteria were found, 363 and 319, respectively. Then, after reviewing the bibliography, duplicates were removed $(n=103)$ and the selected articles were subjected to a subsequent verification by the co-authors. After this, the articles were selected based on the title and abstract. Subsequently, papers describing the application of different methods to $\mathrm{CE}, \mathrm{CE}$ used only for qualitative information or using $\mathrm{CE}$ technique to the analysis of bioactive constituents present in garden and ornamental plants, vegetables and fruits, edible products, beverages, human plasma, blood serum and urine, were eliminated. There were 466 abstracts and papers that were not qualified for this review. One hundred and thirteen articles found in the PubMed and Web of Science databases were used to review the analysis of various bioactive compounds using CE in medicinal plants and herbal drugs.

\subsection{Capillary Zone Electrophoresis}

The largest number of reported methods for the determination of secondary metabolites in plant material and active substances in herbal medicines recorded in the current systematic review is based on the technique of capillary zone electrophoresis with UV detection. Although the fact that most analytes were determined by molecular absorption, other detection methods, such as fluorometric or electrochemical methods (conductometry, amperometry and potentiometry), were also applied (See Table 1).

In order to obtain a satisfactory separation and quantification of analytes, it is essential to optimize several parameters such as type of capillary, $\mathrm{pH}$, voltage, injection mode, buffer composition and concentration, additives (type and concentration), etc. This scrutiny reveals that the most suitable BGE to achieve good separation and quantification of different analytes in CZE is borate buffer.

\subsubsection{Separation in CZE}

In some cases, adequate separation or quantification with borate buffer as a background electrolyte may be difficult, especially in plant extracts rich in different secondary metabolites or herbal preparations containing many herbs. In this case, the supplementation of the running buffer with some modifiers is a simple and effective way to improve separation efficiency in CE. The positive influence of organic solvents as BGE modifiers on the quality of the separation is expressed as a number of completely resolved peaks. Honegr and Pospíšlova evaluated the influence of methanol, acetonitrile, 2-propanol, and a mixture of 2-propanol and acetonitrile [20]. Liang et al. proved that the addition of $\beta$ cyclodextrin $(\beta-C D)$ and methanol significantly improved the resolution of eight lignans in Forsythia suspensa. Excellent separation was accomplished within $15 \mathrm{~min}$ with borate buffer as BGE with the addition of $2 \mathrm{mM} \beta-\mathrm{CD}$ and $5 \%$ methanol $(v / v)$ at the voltage of $20 \mathrm{kV}$, temperature of $35^{\circ} \mathrm{C}$ and detection wavelength of $234 \mathrm{~nm}$ [21]. An increasingly common approach to increase the resolution between racemic natural products is the addition of cyclodextrins to a running buffer, such as chiral selectors. In addition, microchips are also becoming a popular strategy [22]. In the determination of arecoline by Xiang et al., the additive IL, 1-butyl-3-methylimidazolium tetrafluoroborate $\left(\mathrm{BMImBF}_{4}\right)$ was responsible not only for improvement of separation selectivity but also in the detection sensitivity of the analyte. This additive made the resistance of the separation buffer much lower than that of the sample solution, which resulted in an enhanced field-amplified electrokinetic injection CE [23]. 


\subsubsection{Detection Sensitivity}

The sensitivity of CE methods is limited by the use of conventional on-line UV detection, which as can be seen in Table 1, is the most common. The path length is rather short due to the capillary diameter, which has a negative influence on the detection sensitivity. This negative phenomenon is usually compensated by the high efficiency and by using low UV wavelengths, but there are also some other ways to overcome this problem. For instance, Song et al. elaborated a CZE method for the determination of aconite alkaloids, where they dissolved the extracts in acetonitrile; in this way they decreased the conductivities of sample solutions. Besides, they used an electro-injection mode which led to a significant improvement in detection sensitivity due to a field-amplified sample stacking effect and values of LOD/LOQ were expressed in nanograms per milliliter [24]. In comparison, the average values of LOQ within the majority of reported studies are in the $\mu \mathrm{g} \mathrm{mL}^{-1}$ level (See Tables 1-5). For the analysis of inorganic and organic compounds (together with medicinal products) in an acidic or basic form, contactless conductivity detection can be implemented to overcome the limitations of optical detectors with low sensitivities. This method of detection can be comparable with CE-UV in some applications [7]. At present, the use of electrochemical detection is restricted mainly to conductivity detection, which is mainly employed for compounds that are difficult to detect by UV absorption. Moreover, the use of potentiometric and amperometric detectors is relatively rare [25]. A low limit of detection (LOD) may be also achieved because of the high sensitivity rendered by laserinduced fluorescence (LIF) detection. Reported studies with applications of CE-LIF are characterized by a limit of detection/quantification at the $\mathrm{ng} \mathrm{mL}^{-1}$ level) for more information, see Table 1). The main disadvantage of fluorescence detection is its necessity for derivatization of the analyte [25]. A microfluidic approach overcomes such inconveniences as poor resolution and poor LOD or LOQ values which herein are reported as microchip capillary electrophoresis coupled with the laser-induced fluorescence (MCE-LIF). This method is characterized by a very small sample and solvent consumption, a short operating time and a high mass sensitivity, which makes it favorable for the determination of minor compounds with fluorescence in complex samples. In a reported paper by Xiao at al., a developed and carefully applied MCE-LIF method for the fast quantification of aloin A and $\mathrm{B}$ present in seven aloe plant species and pharmaceutical formulations was presented. In this instance, the LOQ is expressed in $\mathrm{ng} \mathrm{mL}^{-1}$ [22]. Table 1 shows that in many cases, UV detectors are sufficient for the analysis of active constituents in pharmaceutical formulation or herbal raw material. However, when it comes to analysis of trace analytes in a complex biological matrix, an introduction of extremely sensitive detectors, such as mass spectrometry or laser-induced fluorescence is recommended [26].

Some reports describe the fabrication and subsequent application of novel detection electrodes for determining the bioactive ingredients by $\mathrm{CE}$, for instance in Belamcandae rhizome [27], in Bergeniae rhizoma [28] and in Cacumen platycladi [29]. In those cases, the values of LOD/LOQ were also as low as ng per $\mathrm{mL}^{-1}$. This approach gives better sensitivity, a considerably lower operating potential, an agreeable resistance to surface fouling, lower operating costs and enhanced stability. Not only does amperometric detection give impressive results, but also, a combination of high separation power of capillary electrophoresis with a high sensitivity of chemiluminescence is becoming very desirable. Wang et al. achieved ultrasensitive determination of epicatechin, rutin, and quercetin by $\mathrm{CE}$ with chemiluminescence detection with limits of detection expressed even in $\mathrm{pg} \mathrm{mL}^{-1}$ [30].

\subsubsection{Sample Pretreatment Techniques in CZE}

Despite its numerous advantages, $\mathrm{CE}$ is still considered a niche technique in separation sciences and the use of CE may be limited due to low sensitivity, which is on account of its short optical path and the small capillary dimensions as well as its small sample volume. To remove this inconvenience, sample pretreatment techniques are introduced to the $\mathrm{CE}$ system in order to achieve a lower LOD for many analytes, shorten the analysis time, reduce sample consumption, and decrease overall analysis cost. Sample pretreatment is essential 
for complex matrices, and especially for biological samples. Sample pretreatment may be either attached to $\mathrm{CE}$ through a dedicated interface (in-line mode) or online, i.e., unified with the $C E$ separation space during or after sample injection. Liquid phase microextraction and solid phase microextraction are most frequently used as pretreatment techniques prior to sample injection. Among electrophoretic preconcentration techniques during/after sample injection one can distinguish: field-amplified/enhanced sample stacking, large volume sample stacking, field amplified/enhanced sample injection, sweeping, micelle to solvent stacking, isotachophoresis, transient isotachophoresis, and more [26].

For the utilization of pre-concentration techniques, Deng et al. elaborated a rapid and simple CE method for the separation and determination of two alkaloids in Ephedra herbs. They used a background electrolyte composed of $80 \mathrm{mM}$ of $\mathrm{NaH}_{2} \mathrm{PO}_{4}$ (pH 3.0) with an addition of $15 \mathrm{mM}$ of $\beta$-cyclodextrin and $0.3 \%$ of hydroxypropyl methyl-cellulose. In this study, the authors took advantage of the field-amplified sample injection and, in the presence of a low conductivity solvent plug, they achieved an approximately 1000-fold improvement in detection sensitivity in comparison to conventional sample injection without any negative impact on resolution [31]. On the other hand, Honegr et al. used large volume sample stacking with polarity switching in order to enhance sensitivity. In this study, sample injection represented $50 \%$ of capillary volume and polarity was switched at $1.6 \mathrm{~min}$ of analysis, under optimized conditions an average 90-fold heightening of absorbance signal of the analytes was accomplished [32]. The abovementioned authors, Honegr and Pospíšilova, also found a method for the determination of phenolic acids in plant extracts using capillary zone electrophoresis with on-line transient isotachophoretic preconcentration (tITP). The application of preconcentration techniques in this case enabled the injection of large plugs of low concentration samples without overloading the column capacity of the electrophoretic system and consequently led to low detection limits without any decline in separation efficiency [20].

The implementation of extraction techniques prior to separation and detection by capillary electrophoresis is the right approach to obtain an exceedingly sensitive determination. In Table 1 one can find that Zhang et al. employed solid-phase microextraction (SPME) for $\mathrm{CE}$ determination of three protoberberines. This group of researchers fabricated a pipettebased device for their new imprinted monolith-based SPME-CE method, which was used for loading, subsequent extraction and final elution of a sample. The positive influence of the addition of methanol to BGE on separation was also noticed. The study confirmed that three protoberberines can be well enriched by the use of imprinted SPME. The limits of detection obtained were lower than in previously reported methods, i.e., $0.1 \mu \mathrm{g} \mathrm{mL}{ }^{-1}$ [32]. Wang et al. described the application of subcritical water extraction (SWE) for the determination of alkaloids in Sophora. This relatively new extraction technique was beneficial in terms of operation time, efficiency and lack of organic solvent consumption. Moreover, the electro-injection boosted reproducibility in capillary electrophoresis with field-amplified stacking through the addition of acid to the sample [33].

\subsubsection{Time of Analysis}

An important issue for CE methods and in general for the establishment of a drug quality control method is analysis time. Literature analysis shows that it can be reduced even to $4 \mathrm{~min}$. This impressively short time of analysis is reported by Du and Wang, who applied CE for the determination of berberine in herbal medications [34].

\subsubsection{CE or HPLC?}

Analytical methods elaborated for quality control of herbal preparations based on CE techniques may be an attractive alternative, because of the short analysis time, good separation efficiency, minimal sample, and solvent requirements. However, there is a question of whether $\mathrm{CE}$ is able to give comparable results with high performance liquid chromatography (HPLC). In some cases, one can find an interesting answer, for instance, there was no significant difference between the two methods established by Chen et al. 
using HPLC and CE to determine nine marker components in "samgiumgagambang" (SGMX, herbal medicinal preparation containing 14 herbs) on the basis of the results for the five main constituents in SGMX. What is more, CE stood out for its shorter time of operation (14 min vs. $50 \mathrm{~min}$ ) and its higher separation efficiency [10]. Dresler et al. in turn verified that capillary electrophoresis may be an alternative to HPLC for assessing the content of metabolites in Hypericum perforatum and H. annulatum and likewise nonsignificant differences between those two elaborated methods were found (the difference less than $10 \%$ ). However, a comparison between LOD and LOQ values achieved with each method demonstrated the advantage of HPLC over CE with respect to detection sensitivity, but the observed difference between these methods can be significant in the analysis of dilute samples with very small amounts of components [35]. Gufler et al. presented capillary electrophoresis as a rapid and potent technique for the analysis of Urecola rosea leaf extracts. On the one hand, in terms of qualitative and validation parameters, it was equivalent to HPLC. On the other hand, with respect to operation time and environmental sustainability, CE is definitely beneficial and may be an attractive alternative to HPLC [36]. Table 1 confirms the reader's opinion that low concentration sensitivity remains a challenge and is the subject of the continuous development of capillary electrophoresis.

\subsubsection{Interactions between Analytes and Additives to the BGE}

CZE separation is based on the differences between the electrophoretic mobilities of separated compounds. The development of the technique in the form of affinity electrophoresis allows us to obtain highly specific separation through the use of specific ligands (for instance, selective antibodies, proteins, metal ions, or lectins). It should be highlighted that specific interactions between analytes and ligands affect mobility; moreover, they provide possibilities for the isolation and detection of analytes from complex matrices [37]. It is well-established that two main factors influence the electrophoretic mobility, namely the intrinsic physical characteristics of the analyzed compound and chemical additives in BGE interacting with the analyte [38]. Secondary equilibria resulting from additive-analyte interactions are essential to accomplish good resolution. Despite the fact that borate buffer was the most frequently used as a background electrolyte in reported works, various organic solvents and compounds were also added to the BGE to optimize the separations; for instance, surfactants, neutral salts, organic amines, organic salts, and chiral selectors (see Table 1). On the one hand, those additives obviously have an impact on mobility. On the other hand, Table 1 reveals that additives and organic solvents, especially when they go hand in hand with sample pretreatment/preconcentration, have an influence on the detection performance, even when a conventional UV detection is used. Organic solvents and additives are totally different from water, but also from one another in terms of physical and chemical properties. Different solvent properties (in particular $\mathrm{pH}$ ) strongly influence the acid-base behavior and generally increase the $\mathrm{pKa}$ values of analytes (significantly different in organic-water mixtures in comparison to aqueous media), electrophoretic mobility, and give more opportunities to control the overall separation processes, manipulate selectivity and to achieve separations unworkable in aqueous buffer [39-41]. During the optimization of $\mathrm{CE}$ conditions, it should be taken into consideration that the $\mathrm{pKa}$ values of acids and bases may be totally different in aqueous and nonaqueous media due to differences in dielectric constant between solvents, which also impacts on the mobilities of divalent ionic species, absorbance to the wall of the capillary, and finally affects the electroosmotic flow [42]. Apart from the effects of organic solvents on the acid-base properties of analyzed compounds, ion-ion interactions resulting from the presence of buffer electrolytes as well as other ionic modifiers in the background electrolyte and ion-solvent interactions could considerably impact the analyte's electrophoretic mobility [41]. An unwanted phenomenon of poor reproducibility in migration time occurs when analyte absorption onto the capillary wall changes its conditions and, as a result, affects the magnitude of electroosmotic flow. This happens especially when a bare fused silica capillary is employed for analysis and it is little wonder that the interaction between samples and the inner capillary's wall affects 
peak shape, resolution, and efficiency. This light capillary coating and surface modification establishes a good direction for future research and development of the technique [43].

\subsubsection{Field of Application}

Methods based on capillary zone electrophoresis may be successfully employed, even for a full-scale quality analysis of herbal formulations, as was proved in the study reported by $\mathrm{Xu}$ et al. In this study, a comprehensive, rapid, and accomplishable electrophoretic method for the simultaneous separation and determination of seven constituents in Guan-Xin-Ning injection was elaborated and subsequently employed for quality control purposes [44].

CZE was successfully employed for the quantification of different classes of secondary metabolites in plant extracts among others: phenolic compounds, coumarins, protoberberines, curcuminoids, inorganic cations, isoquinoline alkaloids, iridoid glycosides, benzoic acid compounds quinolizidine alkaloids, and triterpene acids. This technique was also used for the determination of various active constituents and adulterants in herbal formulations. This kind of utilization is extremely important for the quality control of herbal medicinal preparations (for details see Table 1). A detailed analysis of the column entitled "Remarks" confirms the abovementioned ways to increase separation performance and detection sensitivity of capillary zone electrophoresis.

Table 1. Application of capillary zone electrophoresis.

\begin{tabular}{|c|c|c|c|c|c|c|}
\hline Sample & Analytes & BGE & Detection & $\begin{array}{c}\mathrm{LOQ} \\
\left(\mu \mathrm{g} \mathrm{mL}^{-1}\right)\end{array}$ & Remarks & Ref. \\
\hline $\begin{array}{l}\text { "samgiumgagambang" } \\
\text { (SGMX) }\end{array}$ & $\begin{array}{l}\text { 5-hydroxymethyl- } \\
\text { furaldehyde, } \\
\text { geniposidic acid, } \\
\text { chlorogenic acid, } \\
\text { paeoniflorin, } \\
20- \\
\text { hydroxyecdysone, } \\
\text { coptisine, berberine, } \\
\text { luteolin and } \\
\text { glycyrrhizic acid }\end{array}$ & $\begin{array}{c}70 \mathrm{mM} \text { borate } \\
\text { buffer containing } \\
10 \% \text { methanol } \\
\text { (pH 9.5) }\end{array}$ & $\begin{array}{c}\text { UV } \\
(230 \mathrm{~nm})\end{array}$ & $5.0-100.0$ & $\begin{array}{l}\text { no significant } \\
\text { difference } \\
\text { between } \\
\text { HPLC and CE } \\
\text { results }\end{array}$ & [10] \\
\hline $\begin{array}{l}12 \text { herbal } \\
\text { preparations used for } \\
\text { the treatment } \\
\text { of diabetes }\end{array}$ & $\begin{array}{l}\text { metformin, } \\
\text { chlorpropamide, } \\
\text { glibenclamide } \\
\text { and gliclazide }\end{array}$ & $\begin{array}{l}\text { sodium acetate } \\
20 \mathrm{mM} \mathrm{L}^{-1} \\
(\mathrm{pH} \mathrm{10.0)}\end{array}$ & $\mathrm{CM}$ & $\begin{array}{l}3.21,2.01 \\
4.46 \text { and } \\
5.77\end{array}$ & $\begin{array}{l}\text { determination } \\
\text { of } \\
\text { hypo- } \\
\text { glycemics as } \\
\text { adulterants }\end{array}$ & [7] \\
\hline 26 herbal formulations & $\begin{array}{c}\text { furosemide, } \\
\text { hydrochlorothiazide, } \\
\text { chlorthalidone, } \\
\text { amiloride, } \\
\text { phenolphthalein, } \\
\text { amfepramone, } \\
\text { fluoxetine and } \\
\text { paroxetine }\end{array}$ & $\begin{array}{l}\text { phosphate buffer } \\
\text { (pH 9.2) }\end{array}$ & $\mathrm{CM}$ & $\begin{array}{l}5.14-11.01 \\
\mathrm{mg} / \mathrm{kg}\end{array}$ & $\begin{array}{l}\text { determination } \\
\text { of adulterants } \\
\text { in herbal } \\
\text { formulations } \\
\text { for weight } \\
\text { loss }\end{array}$ & [9] \\
\hline $\begin{array}{c}7 \text { Aloe plant species, } 10 \\
\text { Aloe pharmaceutical } \\
\text { preparations }\end{array}$ & aloin $\mathrm{A}$ and $\mathrm{B}$ & $\begin{array}{c}20.0 \mathrm{mM} \text { borate } \\
\text { buffer with } \\
50 \mathrm{mM} \text { SDS and } \\
10 \mathrm{mM} \\
\beta-\mathrm{CD}(\mathrm{pH} 9.3)\end{array}$ & LIF & 0.025 & $\begin{array}{l}\text { microchip } \\
\text { capillary elec- } \\
\text { trophoresis } \\
(\mathrm{MCE})\end{array}$ & [22] \\
\hline Abelia triflora extract & $\begin{array}{l}\text { scutellarein and } \\
\text { caffeic acid }\end{array}$ & $\begin{array}{c}40 \mathrm{mM} \text { borax } \\
\text { buffer (pH 9.2) }\end{array}$ & $\begin{array}{c}\text { UV } \\
(200 \mathrm{~nm})\end{array}$ & 2.5 & & [45] \\
\hline
\end{tabular}


Table 1. Cont.

\begin{tabular}{|c|c|c|c|c|c|c|}
\hline Sample & Analytes & BGE & Detection & $\begin{array}{c}\mathrm{LOQ} \\
\left(\mu \mathrm{g} \mathrm{mL^{-1 } )}\right.\end{array}$ & Remarks & Ref. \\
\hline Aconite radix & $\begin{array}{c}\text { aconitine, } \\
\text { mesaconitine, } \\
\text { hypaconitine, } \\
\text { benzoylaconine, } \\
\text { benzoylmesaconine } \\
\text { and } \\
\text { benzoylhypaconine }\end{array}$ & $\begin{array}{l}200 \mathrm{mM} \text { Tris, } \\
150 \mathrm{mM} \\
\text { perchloric acid } \\
\text { and } 40 \% \\
\text { 1,4-dioxane } \\
\text { (pH 7.8) }\end{array}$ & $\begin{array}{c}\text { UV } \\
(214 \mathrm{~nm})\end{array}$ & $\begin{array}{c}0.14,0.13 \\
0.14,0.14 \\
0.13 \text { and } \\
0.15\end{array}$ & $\begin{array}{l}\mathrm{LOD} / \mathrm{LOQ} \\
\mathrm{ng} \mathrm{mL}\end{array}$ & [24] \\
\hline $\begin{array}{l}\text { Aconitum carmichaeli } \\
\text { (Aconiti radix: Chinese } \\
\text { name: chuanwu) }\end{array}$ & $\begin{array}{c}\text { aconitine, } \\
\text { mesaconitine and } \\
\text { hypaconitine }\end{array}$ & $\begin{array}{l}25 \text { mM borax- } \\
20 \text { mM 1-ethyl-3- } \\
\text { methylimidazo- } \\
\text { lium } \\
\text { tetrafluoroborate } \\
\quad \text { (pH 9.15) }\end{array}$ & ECL & $\begin{array}{c}5.62 \times 10^{-8} \\
2.78 \times 10^{-8} \\
3.50 \times 10^{-9} \\
\mathrm{~mol} \mathrm{~L}^{-1} \\
0.036,0.018 \\
\text { and } 0.002\end{array}$ & $\begin{array}{c}\mathrm{LOD} / \mathrm{LOQ} \\
\mathrm{ng} \mathrm{mL}\end{array}$ & [46] \\
\hline $\begin{array}{c}\text { Aesculus hippocastanum } \\
\text { (dry, hydro-alcoholic } \\
\text { and hydroglycolic } \\
\text { extracts) }\end{array}$ & $\beta$-escin & $\begin{array}{l}25 \mathrm{mMol} \mathrm{L}^{-1} \\
\text { bicarbonate- } \\
\text { carbonate buffer } \\
\text { (pH 10.3) }\end{array}$ & $\begin{array}{c}\text { UV } \\
(226 \mathrm{~nm})\end{array}$ & 38760 & & [47] \\
\hline $\begin{array}{l}\text { Aesculus hippocastanum } \\
\text { L., Cichorium intybus L., } \\
\text { Melilotus officinalis L. } \\
\text { and } \\
\text { Juniperus communis L. } \\
\text { "Pendula" }\end{array}$ & $\begin{array}{l}\text { aesculin, aesculetin, } \\
\text { umbelliferone, } \\
\text { dihydrocoumarin }\end{array}$ & $\begin{array}{c}20 \text { mM borax in } \\
5 \% \text { methanol } \\
(\mathrm{pH} 10.1)\end{array}$ & $\begin{array}{l}\text { UV } \\
(194 \text { and } \\
206 \mathrm{~nm})\end{array}$ & $0.4-2.5 \mathrm{ppm}$ & & [48] \\
\hline Areca nut & $\begin{array}{c}\text { arecoline } \\
\text { (methyl-1,2,5,6- } \\
\text { tetrahydro-1- } \\
\text { methylnicotinate) }\end{array}$ & $\begin{array}{c}20 \mathrm{mMol} \mathrm{L}^{-1} \\
\text { phosphate with } \\
10 \mathrm{mMol} \mathrm{L}^{-1} \\
\mathrm{BMImBF}_{4} \text { buffer } \\
\text { (pH 7.50) }\end{array}$ & ECL & 0.00077 & $\begin{array}{l}\mathrm{LOD} / \mathrm{LOQ} \\
\mathrm{pg} \mathrm{mL}\end{array}$ & [23] \\
\hline Belamcandae rhizoma & $\begin{array}{l}\text { tectoridin and } \\
\text { irigenin }\end{array}$ & $\begin{array}{l}\text { borate buffer } \\
\quad(\mathrm{pH} 9.8)\end{array}$ & AM & $\begin{array}{l}\text { nd, LOD: } \\
0.111 \text { and } \\
0.076\end{array}$ & $\begin{array}{c}\text { detection } \\
\text { electrode } \\
\text { based on the } \\
\text { composite of } \\
\text { carbon } \\
\text { nanotubes } \\
\text { and polylactic } \\
\text { acid }\end{array}$ & [27] \\
\hline Bergeniae rhizoma & arbutin and bergenin & $\begin{array}{c}50 \mathrm{mM} \text { borate } \\
\text { buffer (pH 9.2) }\end{array}$ & AM & $\begin{array}{c}0.057 \text { and } \\
0.076\end{array}$ & $\begin{array}{l}\text { carbon } \\
\text { nanotube- } \\
\text { epoxy } \\
\text { composite } \\
\text { electrode }\end{array}$ & [28] \\
\hline Cacumen platycladi & $\begin{array}{l}\text { rutin, quercitrin, } \\
\text { kaempferol and } \\
\text { quercetin }\end{array}$ & $\begin{array}{l}50 \mathrm{mM} \text { sodium } \\
\text { borate buffer } \\
(\mathrm{pH} 9.2)\end{array}$ & $\mathrm{AM}$ & $\begin{array}{l}0.110,0.085 \\
0.063,0.070\end{array}$ & $\begin{array}{l}\text { a fabricated } \\
\text { graphene/poly } \\
\text { (ethylene-co- } \\
\text { vinyl acetate) } \\
\text { composite } \\
\text { electrode }\end{array}$ & [29] \\
\hline
\end{tabular}


Table 1. Cont.

\begin{tabular}{|c|c|c|c|c|c|c|}
\hline Sample & Analytes & BGE & Detection & $\begin{array}{c}\mathrm{LOQ} \\
\left(\mu \mathrm{g} \mathrm{mL^{-1 } )}\right.\end{array}$ & Remarks & Ref. \\
\hline $\begin{array}{c}\text { Camptotheca acuminata } \\
\text { (Camptotheca bark and } \\
\text { fruit) }\end{array}$ & $\begin{array}{c}\text { camptothecin } \\
\text { alkaloids (CPT, } \\
\text { 9-ACPT 9-MCPT } \\
\text { HCPT, 7-EHCPT) }\end{array}$ & $\begin{array}{c}25 \mathrm{mM} \text { borate } \\
\text { buffer containing } \\
20 \mathrm{mM} \\
\text { Sulfobutylether- } \\
\beta-\mathrm{CD} \text { and } 20 \mathrm{mM} \\
\text { ionic liquid } \\
\text { [EMIM] [L-Lac] } \\
(\mathrm{pH} 9.0)\end{array}$ & $\begin{array}{c}\text { UV } \\
(254 \mathrm{~nm})\end{array}$ & $\begin{array}{c}0.00020- \\
0.00078\end{array}$ & $\begin{array}{l}\text { Large- } \\
\text { volume } \\
\text { sample } \\
\text { stacking }\end{array}$ & [49] \\
\hline $\begin{array}{c}\text { Cassia tora } \\
\text { (Cassiae semen and } \\
\text { Cassia seed tea) }\end{array}$ & $\begin{array}{c}\text { physcion, } \\
\text { aloe-emodin, } \\
\text { chrysophanol, } \\
\text { emodin, } \\
\text { aurantio-obtusin, } \\
\text { rhein }\end{array}$ & $\begin{array}{c}10 \mathrm{mM} \mathrm{Na}_{2} \mathrm{HPO}_{4} \\
\text { and } 6 \mathrm{mM} \\
\mathrm{Na}_{3} \mathrm{PO}_{4} 15 \% \\
\text { methanol }(v / v) \\
(\mathrm{pH} \mathrm{11.8)}\end{array}$ & $\begin{array}{c}\text { UV } \\
(254 \mathrm{~nm})\end{array}$ & $1.11-4.67$ & $\begin{array}{l}\text { an accelerated } \\
\text { solvent } \\
\text { extraction } \\
\text { procedure }\end{array}$ & [50] \\
\hline Catha edulis & $\begin{array}{l}\text { cathinone, cathine, } \\
\text { and phenyl- } \\
\text { propanolamine }\end{array}$ & $\begin{array}{c}25 \text { mM TRIS } \\
\text { phosphate buffer } \\
\text { (pH 2.5) }\end{array}$ & $\begin{array}{c}\text { UV } \\
(210 \mathrm{~nm})\end{array}$ & 0.4 & & [51] \\
\hline $\begin{array}{l}\text { Chamomile and } \\
\text { linden flower } \\
\text { extracts }\end{array}$ & $\begin{array}{c}\text { apigetrin, naringin, } \\
\text { naringenin, catechin, } \\
\text { galangin, apigenin, } \\
\text { luteolin, quercetin, } \\
\text { myricetin, } \\
\text { kaempferol and } \\
\text { kaempferide }\end{array}$ & $\begin{array}{l}40 \mathrm{mM} \text { borate } \\
\text { buffer (pH 8.9) }\end{array}$ & $\begin{array}{c}\text { UV } \\
(210 \mathrm{~nm})\end{array}$ & $0.252-2.142$ & & [52] \\
\hline Chelidonium majus L & $\begin{array}{l}\text { protopine, } \\
\text { chelidonine, } \\
\text { coptisine, } \\
\text { sanguinarine, } \\
\text { allocryptopine, } \\
\text { chelerythrine, and } \\
\text { stylopine }\end{array}$ & $\begin{array}{l}20 \text { mM phosphate } \\
\text { buffer (pH 3.1) }\end{array}$ & UV-LEDIF & $0.06-5.5$ & & [53] \\
\hline $\begin{array}{l}\text { Chuanxiong rhizoma } \\
\text { (Ligusticum wallichii) }\end{array}$ & $\begin{array}{l}\text { vanillin, ferulic acid, } \\
\text { vanillic acid, caffeic } \\
\text { acid and } \\
\text { protocatechuic acid }\end{array}$ & $\begin{array}{l}50 \mathrm{mM} \text { borate } \\
\text { buffer ( } \mathrm{pH} 9.2)\end{array}$ & AM & nd & $\begin{array}{c}\text { carbon } \\
\text { nanotube } \\
(\mathrm{CNT})- \\
\text { polydimethyl- } \\
\text { siloxane } \\
\text { (PDMS) } \\
\text { composite } \\
\text { electrode }\end{array}$ & [54] \\
\hline $\begin{array}{c}\text { Combretum aculeatum } \\
\text { extracts }\end{array}$ & punicalagin & $\begin{array}{c}25 \mathrm{mM} \\
\text { phosphate buffer } \\
\text { (pH 7.4) }\end{array}$ & $\begin{array}{c}\text { UV } \\
(280 \mathrm{~nm})\end{array}$ & 60 ppm & & [55] \\
\hline $\begin{array}{l}\text { Connarus perrottetii var. } \\
\text { angustifolius (aqueous } \\
\text { infusions, ethanolic } \\
\text { extracts and butanolic } \\
\text { extracts) }\end{array}$ & catechin and rutin & $\begin{array}{c}20 \mathrm{mM} \text { borate } \\
\text { buffer containing } \\
15 \% \text { methanol } \\
(v / v), \\
(\mathrm{pH} 9.2)\end{array}$ & $\begin{array}{c}\text { UV } \\
(230 \mathrm{~nm})\end{array}$ & $\begin{array}{l}0.97 \text { and } \\
2.46\end{array}$ & & [56] \\
\hline $\begin{array}{c}\text { Coptidis rhizoma and } \\
\text { berberine } \\
\text { hydrochloride } \\
\text { tablets }\end{array}$ & berberine & $\begin{array}{c}10 \mathrm{mM} \mathrm{L}^{-1} \text { PBS } \\
(\mathrm{pH} 7.81)\end{array}$ & ECL & 0.005 & $\begin{array}{l}\mathrm{LOD} / \mathrm{LOQ} \\
\mathrm{ng} \mathrm{mL}\end{array}$ & [34] \\
\hline
\end{tabular}


Table 1. Cont.

\begin{tabular}{|c|c|c|c|c|c|c|}
\hline Sample & Analytes & BGE & Detection & $\begin{array}{c}\mathrm{LOQ} \\
\left(\mu \mathrm{g} \mathrm{mL^{-1 } )}\right.\end{array}$ & Remarks & Ref. \\
\hline Coreopsis tinctoria Nutt. & $\begin{array}{c}\text { taxifolin-7-O- } \\
\text { glucoside, } \\
\text { flavanomarein, } \\
\text { quercetagetin-7-O- } \\
\text { glucoside, okanin } \\
4^{\prime}-\mathrm{O}-\text { glucoside, } \\
\text { okanin and } \\
\text { chlorogenic acid }\end{array}$ & $\begin{array}{c}50 \mathrm{mM} \text { borate } \\
\text { buffer containing } \\
\text { 15\% acetonitrile } \\
\text { (pH 9.0) }\end{array}$ & UV (280) & $2.34-12.94$ & & [57] \\
\hline Daturae flos & $\begin{array}{l}\text { atropine, } \\
\text { scopolamine, and } \\
\text { anisodamine }\end{array}$ & $\begin{array}{c}40 \mathrm{mM} \text { phosphate } \\
\text { buffer containing } \\
20 \% v / v \\
\text { methanol and } \\
30 \% v / v \\
\text { acetonitrile } \\
\text { (pH 7.0) }\end{array}$ & $\begin{array}{c}\text { UV } \\
(196 \mathrm{~nm})\end{array}$ & $\begin{array}{c}0.50 \\
(\mathrm{LOD})\end{array}$ & $\begin{array}{l}\text { capillary } \\
\text { coated by } \\
\text { graphene } \\
\text { oxide }\end{array}$ & [58] \\
\hline $\begin{array}{l}\text { Duyiwei capsule and } \\
\text { dried crude drug of } \\
\text { Lamiophlomis rotata }\end{array}$ & $\begin{array}{c}8-\mathrm{O}- \\
\text { acetylshanzhiside } \\
\text { methylester and } \\
\text { 8-deoxyshanzhiside, } \\
\text { apigenin, quercetin } \\
\text { and luteolin }\end{array}$ & $\begin{array}{l}10 \mathrm{mM} \text { sodium } \\
\text { tetraborate- } \\
20 \mathrm{mM} \\
\mathrm{NaH}_{2} \mathrm{PO}_{4}-15 \% \\
(v / v) \text { methanol } \\
(\mathrm{pH} 8.5)\end{array}$ & $\begin{array}{c}\text { UV } \\
(238 \mathrm{~nm})\end{array}$ & $\begin{array}{l}\text { nd, nd, } \\
\text { LOD: } \\
2.6-9.2\end{array}$ & & [59] \\
\hline $\begin{array}{l}\text { Echium vulgare L. and } \\
\text { Echium } \\
\text { russicum L. radix }\end{array}$ & $\begin{array}{l}\text { shikonin and } \\
\text { rosmarinic acid }\end{array}$ & $\begin{array}{l}50 \mathrm{mM} \text { borate } \\
\text { buffer (pH 9.5) }\end{array}$ & $\begin{array}{c}\text { UV } \\
(218 \text { and } \\
202 \mathrm{~nm})\end{array}$ & $\begin{array}{l}\text { nd, LOD: } \\
0.603 \text { and } \\
0.270 \mathrm{ppm}\end{array}$ & & [60] \\
\hline Ephedra sinica herba & $\begin{array}{l}\text { ephedrine and } \\
\text { pseudoephedrine }\end{array}$ & $\begin{array}{c}80 \mathrm{mM}^{\circ} \\
\mathrm{NaH}_{2} \mathrm{PO}_{4}, \\
15 \mathrm{mM} \text { of } \beta-\mathrm{CD} \\
\text { and } 0.3 \% \text { of } \\
\text { hydroxypropyl } \\
\text { methyl-cellulose } \\
\text { (pH 3.0) }\end{array}$ & $\begin{array}{c}\text { UV } \\
(214 \mathrm{~nm})\end{array}$ & $\begin{array}{l}\text { nd, LOD: } \\
0.7 \text { and } 0.6\end{array}$ & $\begin{array}{l}\text { Field- } \\
\text { Amplified } \\
\text { Sample } \\
\text { Injection }\end{array}$ & [31] \\
\hline $\begin{array}{c}\text { Epilobium parviflorum } \\
\text { extracts }\end{array}$ & $\begin{array}{l}\text { caffeic acid, cinnamic } \\
\text { acid, p-coumaric } \\
\text { acid, ferulic acid, } \\
\text { protocatechuic acid, } \\
\text { syringic acid and } \\
\text { vanilic acid }\end{array}$ & $\begin{array}{c}200 \mathrm{mM} \text { borate } \\
\text { buffer with } 37.5 \% \\
\text { methanol, } 0.001 \% \\
\text { hexadimethrine } \\
\text { bromide, and } \\
15 \text { mM 2- } \\
\text { hydroxypropyl- } \\
\beta-\mathrm{CD} \\
(\mathrm{pH} \mathrm{9.2)}\end{array}$ & $\begin{array}{c}\text { UV } \\
(214 \mathrm{~nm})\end{array}$ & $0.032-0.094$ & $\begin{array}{l}\text { On-line } \\
\text { transient iso- } \\
\text { tachophoretic } \\
\text { preconcentra- } \\
\text { tion }\end{array}$ & [20] \\
\hline $\begin{array}{c}\text { Epimedii herba } \\
\text { (Yin-Yang-Huo) }\end{array}$ & $\begin{array}{l}\text { epimedin } \mathrm{C} \text {, icariin, } \\
\text { diphylloside A, } \\
\text { epimedoside A and } \\
\text { icarisoside A }\end{array}$ & $\begin{array}{l}30 \mathrm{mM} \text { borate } \\
\text { buffer containing } \\
40 \% \text { methanol } \\
\text { (pH 9.5) }\end{array}$ & $\begin{array}{c}\text { UV } \\
(270 \mathrm{~nm})\end{array}$ & $\begin{array}{l}3.0,2.0,4.0, \\
2.0 \text { and } 3.0\end{array}$ & $\begin{array}{l}\text { coupled with } \\
\text { SPE }\end{array}$ & [61] \\
\hline $\begin{array}{l}\text { Fengshi Maqian tablets } \\
\text { and Yaotongning } \\
\text { capsules }\end{array}$ & $\begin{array}{l}\text { strychnine and } \\
\text { brucine }\end{array}$ & $\begin{array}{l}75 \mathrm{mM} \text { phosphate } \\
\text { buffer with } 30 \% \\
\text { methanol }(v / v) \\
(\mathrm{pH} 2.5)\end{array}$ & $\begin{array}{c}\text { UV } \\
(203 \mathrm{~nm})\end{array}$ & 0.01 & $\begin{array}{l}\text { sample pre- } \\
\text { concentration } \\
\text { method by } \\
\text { two-step } \\
\text { stacking }\end{array}$ & [62] \\
\hline
\end{tabular}


Table 1. Cont.

\begin{tabular}{|c|c|c|c|c|c|c|}
\hline Sample & Analytes & BGE & Detection & $\begin{array}{c}\mathrm{LOQ} \\
\left(\mu \mathrm{g} \mathrm{mL^{-1 } )}\right.\end{array}$ & Remarks & Ref. \\
\hline Forsythia suspensa & $\begin{array}{l}\text { galacturonic acid and } \\
\text { glucuronic acid }\end{array}$ & $\begin{array}{l}130 \text { mM sodium } \\
\text { hydroxide, } \\
36 \text { mM disodium } \\
\text { hydrogen } \\
\text { phosphate } \\
\text { dihydrate and } \\
0.5 \mathrm{mM} \\
\text { cetyltrimethylam- } \\
\text { monium bromide } \\
\text { (pH 12.28) }\end{array}$ & $\begin{array}{c}\text { UV } \\
(270 \mathrm{~nm})\end{array}$ & $\begin{array}{l}10.68 \text { and } \\
12.64\end{array}$ & $\begin{array}{l}\text { reversed elec- } \\
\text { troosmotic } \\
\text { flow (EOF) } \\
\text { to improve } \\
\text { separation of } \\
\text { neutral sugars }\end{array}$ & [63] \\
\hline $\begin{array}{l}\text { Forsythia suspensa } \\
\text { fructus and commercial } \\
\text { extracts }\end{array}$ & $\begin{array}{l}\text { phillyrin, phillygenin, } \\
\text { epipinoresinol-4-O- } \\
\beta \text {-glucoside, } \\
\text { pinoresinol-4-O- } \beta- \\
\text { glucoside, } \\
\text { lariciresinol, } \\
\text { pinoresinol, } \\
\text { isolariciresinol and } \\
\text { vladinol D }\end{array}$ & $\begin{array}{c}40 \mathrm{mM} \text { borate } \\
\text { buffer containing } \\
2 \mathrm{mM} \beta-\mathrm{CD} \text { and } \\
5 \% \text { methanol } \\
(v / v)(\mathrm{pH} 10.30)\end{array}$ & $\begin{array}{c}\text { UV } \\
(234 \mathrm{~nm})\end{array}$ & $3.00-4.38$ & & [21] \\
\hline $\begin{array}{l}\text { Forsythiae suspensae } \\
\text { fructus }\end{array}$ & $\begin{array}{l}\text { oleanolic acid, ursolic } \\
\text { acid and betulinic } \\
\text { acid }\end{array}$ & $\begin{array}{c}50.0 \mathrm{mM} \mathrm{L}^{-1} \\
\text { borax and } \\
0.5 \mathrm{mM} \mathrm{L}^{-1} \\
\beta-\text { cyclodextrin } \\
(\beta-\mathrm{CD})(\mathrm{pH} 9.5)\end{array}$ & $\begin{array}{c}\text { UV } \\
(200 \mathrm{~nm})\end{array}$ & $\begin{array}{l}4.8,4.6 \text { and } \\
5.9\end{array}$ & & [30] \\
\hline $\begin{array}{c}\text { Fritillariae Thunbergii } \\
\text { bulbus (chloroform } \\
\text { extracts) }\end{array}$ & $\begin{array}{l}\text { peimine and } \\
\text { peiminine }\end{array}$ & $\begin{array}{c}66 \% \mathrm{MeOH}-\mathrm{ACN} \\
(1: 1, v / v), 34 \% \\
\text { aqueous buffer } \\
\text { containing } \\
15 \mathrm{mM} \mathrm{NaH}_{2} \mathrm{PO}_{4}, \\
2.5 \mathrm{mM} \mathrm{NED} \\
4 \mathrm{mM} \mathrm{H}_{3} \mathrm{PO}_{4} \\
(\mathrm{pH} \mathrm{3.0)}\end{array}$ & $\begin{array}{c}\text { UV } \\
(214 \mathrm{~nm})\end{array}$ & $\begin{array}{l}\text { nd., LOD: } \\
3.9 \text { and } 4.1\end{array}$ & $\begin{array}{l}\text { NED as the } \\
\text { UV absorbing } \\
\text { probe }\end{array}$ & [64] \\
\hline $\begin{array}{c}\text { Garcinia cambogia (fruit } \\
\text { rinds) and Hibiscus } \\
\text { sabdariffa (calyx) }\end{array}$ & $\begin{array}{c}\text { sodium salts of } \\
(1 S, 2 R)- \\
\text { hydroxycitric and } \\
(1 S, 2 S)-\text { hydroxycitric } \\
\text { acids }\end{array}$ & $\begin{array}{l}50 \text { mM sodium } \\
\text { phosphate buffer } \\
\text { (pH 7.0) }\end{array}$ & $\begin{array}{c}\text { UV } \\
(193 \mathrm{~nm})\end{array}$ & $32.89-68.52$ & & [65] \\
\hline Geranii herba & $\begin{array}{l}\text { rutin, hyperin, } \\
\text { kaempferol, corilagin, } \\
\text { geraniin, gallic acid, } \\
\text { and protocatechuic } \\
\text { acid }\end{array}$ & $\begin{array}{l}50 \mathrm{mM} \text { borate } \\
\text { buffer (pH 9.2) }\end{array}$ & $\mathrm{AM}$ & $\begin{array}{l}\text { nd, LOD: } \\
30.9-682.8\end{array}$ & $\begin{array}{l}\text { graphene/poly } \\
\text { methacrylate) } \\
\text { composite } \\
\text { electrode as a } \\
\text { sensitive am- } \\
\text { perometric } \\
\text { detector }\end{array}$ & thyl \\
\hline $\begin{array}{l}\text { Ginkgo biloba extract } \\
\text { and rutin tablet, }\end{array}$ & $\begin{array}{l}\text { epicatechin, rutin, } \\
\text { and quercetin }\end{array}$ & $\begin{array}{l}10.0 \mathrm{mM} \text { borate } \\
\text { and } \\
0.5 \mathrm{mM} \text { luminol } \\
(\mathrm{pH} 8.5)\end{array}$ & CL & $\begin{array}{c}6 \times 10^{-7}, 5 \\
\times 10^{-7} \text { and } \\
1 \times 10^{-6}\end{array}$ & $\begin{array}{l}\text { ultrasensitive } \\
\text { determina- } \\
\text { tion }\end{array}$ & [67] \\
\hline $\begin{array}{l}\text { Glycyrrhiza uralensis } \\
\text { Fisch radix }\end{array}$ & $\begin{array}{l}\text { glycyrrhetinic acid } \\
\text { and glycyrrhizic acid }\end{array}$ & $\begin{array}{l}10 \mathrm{mM} \text { borate } \\
\text { buffer (pH 8.8) }\end{array}$ & UV (268 nm) & 6.2 and 6.9 & $\begin{array}{c}\text { On-line } \\
\text { extraction } \\
\text { coupled with } \\
\text { flow injection } \\
\text { and CE }\end{array}$ & [68] \\
\hline
\end{tabular}


Table 1. Cont.

\begin{tabular}{|c|c|c|c|c|c|c|}
\hline Sample & Analytes & BGE & Detection & $\begin{array}{c}\mathrm{LOQ} \\
\left(\mu \mathrm{g} \mathrm{mL^{-1 } )}\right.\end{array}$ & Remarks & Ref. \\
\hline $\begin{array}{l}\text { Guan-Xin-Ning }(\mathrm{GXN}) \\
\text { injection }\end{array}$ & $\begin{array}{c}\text { caffeic acid, } \\
\text { danshensu, ferulic } \\
\text { acid, isoferulic acid, } \\
\text { salvianolic acid A, } \\
\text { salvianolic acid B, } \\
\text { tertamethylpyrazine }\end{array}$ & $\begin{array}{l}35 \mathrm{mM} \text { SDS and } \\
45 \mathrm{mM} \text { borate } \\
\text { solution (pH 9.3) }\end{array}$ & $\begin{array}{c}\text { UV } \\
(212 \mathrm{~nm})\end{array}$ & $1.5-4.90$ & & [44] \\
\hline $\begin{array}{l}\text { Hippophae rhamnoides } \\
\text { extract and Cerutin }{ }^{\circledR} \\
\text { tablets }\end{array}$ & quercetin and rutin & $\begin{array}{c}40 \mathrm{mM} \mathrm{L}^{-1} \text { borax } \\
(\mathrm{pH} 9.2)\end{array}$ & EC & $\begin{array}{l}0.475 \text { and } \\
0.726\end{array}$ & $\begin{array}{l}\text { hot platinum } \\
\text { microelec- } \\
\text { trodes, flow } \\
\text { injection } \\
\text { analysis }\end{array}$ & [33] \\
\hline Houttuyniae herba & $\begin{array}{l}\text { rutin, isoquercitrin, } \\
\text { quercitrin, and } \\
\text { chlorogenic }\end{array}$ & $\begin{array}{c}50 \mathrm{mM} \text { borate } \\
\text { buffer (pH 9.2) }\end{array}$ & $\mathrm{AM}$ & $\begin{array}{l}41.4,31.8 \\
38.2 \text { and } \\
65.6\end{array}$ & $\begin{array}{l}\text { graphene/polyst } \\
\text { composite } \\
\text { electrode for } \\
\text { amperomet- } \\
\text { ric } \\
\text { detection }\end{array}$ & rene \\
\hline $\begin{array}{c}\text { Hypericum perforatum } \\
\text { and Hypericum } \\
\text { annulatum }\end{array}$ & $\begin{array}{l}\text { chlorogenic acid, } \\
\text { epicatechin, } \\
\text { hyperoside, rutin, } \\
\text { quercitrin and } \\
\text { quercetin }\end{array}$ & $\begin{array}{l}40 \mathrm{mM} \text { borate } \\
\text { buffer, } 50 \mathrm{mM} \\
\text { SDS and } 12 \% \\
\text { acetonitrile }\end{array}$ & $\begin{array}{l}\text { UV }(348,208, \\
370,370 \text { and } \\
318)\end{array}$ & $\begin{array}{l}4.960-9.458 \\
\text { ppm }\end{array}$ & $\begin{array}{l}\text { Non- } \\
\text { significant } \\
\text { differences } \\
\text { between CE } \\
\text { and HPLC }\end{array}$ & [35] \\
\hline Isatidis radix & $\begin{array}{l}\text { benzoic acid, salicylic } \\
\text { acid and } \\
\text { ortho-aminobenzoic } \\
\text { acid }\end{array}$ & $\begin{array}{l}20 \mathrm{mM} \text { borate } \\
\text { and } 30 \mathrm{mM} \\
\text { sodium dodecyl } \\
\text { sulfate buffer } \\
\text { containing } \\
2 \mathrm{mMb}-\mathrm{CD} \text { and } \\
4 \% \text { methanol } \\
(v / v),(\mathrm{pH} 9.8)\end{array}$ & $\begin{array}{c}\text { UV } \\
(250 \mathrm{~nm})\end{array}$ & $\begin{array}{c}\text { nd, } \\
\text { LOD-800 }\end{array}$ & & [70] \\
\hline $\begin{array}{c}\text { Komplex } \\
\text { Kurkumin } \\
{ }^{\circledR} \\
\text { (curcumin } 375 \mathrm{mg}, \\
\text { demethoxycurcumin } \\
100 \text { mg and bis- } \\
\text { demethoxycurcumin } \\
25 \mathrm{mg} \text { ) }\end{array}$ & $\begin{array}{l}\text { curcumin, } \\
\text { demethoxycurcumin } \\
\text { and bisdemethoxy- } \\
\text { curcumin }\end{array}$ & $\begin{array}{c}50 \mathrm{mM} / \mathrm{L} \mathrm{CAPS}^{-1} \\
100 \mathrm{mg} \mathrm{mL}^{-1} \text { of } \\
\mathrm{HP}-\beta-\mathrm{CD} \text { and } 2 \\
\mathrm{gL}-1 \\
\text { of } \mathrm{HEC}\end{array}$ & $\begin{array}{l}\text { UV-VIS } \\
(480 \mathrm{~nm})\end{array}$ & $\begin{array}{l}5.30,4.57 \\
\text { and } 6.20\end{array}$ & $\begin{array}{l}\text { unconventional } \\
\text { hydrodynam- } \\
\text { ically closed } \\
\text { CE systems }\end{array}$ & [71] \\
\hline $\begin{array}{l}\text { Lam-iophlomis } \\
\text { rotate and Cistanche }\end{array}$ & $\begin{array}{l}\text { homovanillyl alcohol, } \\
\text { hydroxytyrosol, 3,4- } \\
\text { dimethoxycinnamic } \\
\text { acid, and caffeic acid }\end{array}$ & $\begin{array}{c}50 \mathrm{mM} \\
\text { borate-100 mM } \\
\text { phosphate buffer } \\
\text { in addition to } \\
5.0 \mathrm{mM} \mathrm{L}^{-1} \\
\beta-\mathrm{CD}(\mathrm{pH} 9.48)\end{array}$ & $\begin{array}{c}\text { UV } \\
(290 \mathrm{~nm})\end{array}$ & $\begin{array}{c}\text { nd, LOD: } \\
0.0051- \\
0.029\end{array}$ & & [72] \\
\hline Lycoridis radiatae bulbus & galanthamine & $\begin{array}{c}18 \mathrm{mMol} \mathrm{L}^{-1} \\
\text { phosphate buffer } \\
\text { (pH 9.0) }\end{array}$ & ECL & $\begin{array}{l}\text { nd, LOD: } \\
0.00025\end{array}$ & & [73] \\
\hline Lycoris radiata & $\begin{array}{l}\text { galanthamine, } \\
\text { homolycorine, } \\
\text { lycorenine and } \\
\text { tazetteine }\end{array}$ & $\begin{array}{l}10.0 \mathrm{mMol} \mathrm{L}^{-1} \\
\text { PBS (pH 8.0) }\end{array}$ & ECL & $\begin{array}{c}\text { nd, LOD: } \\
0.014,0.011 \\
0.0018 \text { and } \\
0.0031\end{array}$ & $\begin{array}{l}\text { Ultrasonic- } \\
\text { assisted } \\
\text { extraction }\end{array}$ & [74] \\
\hline Lysium chinensis folium & $\begin{array}{l}\text { mannitol, sucrose, } \\
\text { glucose, and fructose }\end{array}$ & $50 \mathrm{mM} \mathrm{NaOH}$ & $\mathrm{AM}$ & $\begin{array}{c}0.120,0.394 \\
0.126 \text { and } \\
0.155\end{array}$ & $\begin{array}{l}\text { Far-infrared- } \\
\text { assisted } \\
\text { extraction }\end{array}$ & [75] \\
\hline
\end{tabular}


Table 1. Cont.

\begin{tabular}{|c|c|c|c|c|c|c|}
\hline Sample & Analytes & BGE & Detection & $\begin{array}{c}\mathrm{LOQ} \\
\left(\mu \mathrm{g} \mathrm{mL^{-1 } )}\right.\end{array}$ & Remarks & Ref. \\
\hline $\begin{array}{c}\text { Macleaya cordata and } \\
\text { Chelidonium majus } \\
\text { extracts }\end{array}$ & $\begin{array}{l}\text { chelerythrine and } \\
\text { sanguinarine }\end{array}$ & $\begin{array}{c}40 \mathrm{mM} \\
\text { ammonium } \\
\text { acetate-acetic } \\
\text { acid-water buffer } \\
\text { containing } 50 \% \\
(v / v) \text { formamide } \\
(\mathrm{pH} 2.90)\end{array}$ & LIF & $\begin{array}{l}\text { nd, LOD: } \\
5.0 \text { and } \\
0.002\end{array}$ & $\begin{array}{l}\text { microchip } \\
\text { electrophore- } \\
\text { sis }\end{array}$ & [76] \\
\hline $\begin{array}{c}\text { Magnolia officinalis and } \\
\text { Huoxiang Zhengqi } \\
\text { Liquid. }\end{array}$ & $\begin{array}{l}\text { honokiol and } \\
\text { magnolol }\end{array}$ & $\begin{array}{l}16 \mathrm{mMol} \mathrm{L}^{-1} \\
\text { sodium } \\
\text { tetraborate, } 11 \% \\
\text { methanol } \\
(\mathrm{pH} 10.0)\end{array}$ & $\begin{array}{c}\text { UV } \\
(210 \mathrm{~nm})\end{array}$ & $\begin{array}{l}1670 \text { and } \\
830\end{array}$ & & [77] \\
\hline $\begin{array}{l}\text { Origanum vulgare and } \\
\text { Romanian propolis }\end{array}$ & $\begin{array}{c}\text { resveratrol, } \\
\text { pinostrobin, acacetin, } \\
\text { chrysin, rutin, } \\
\text { naringenin, } \\
\text { isoquercitrin, } \\
\text { umbelliferone, } \\
\text { cinnamic acid, } \\
\text { chlorogenic acid, } \\
\text { galangin, sinapic } \\
\text { acid, } \\
\text { syringic acid, ferulic } \\
\text { acid, kaempferol, } \\
\text { luteolin, } \\
\text { coumaric acid, } \\
\text { quercetin, rosmarinic } \\
\text { acid and } \\
\text { caffeic acid }\end{array}$ & $\begin{array}{l}45 \mathrm{mM} \text { borate } \\
\text { buffer with } \\
0.9 \mathrm{mM} \text { sodium } \\
\text { dodecyl sulfate } \\
\quad(\mathrm{pH}=9.35)\end{array}$ & $\begin{array}{c}\text { UV } \\
(280 \mathrm{~nm})\end{array}$ & $0.07-5.77$ & & [78] \\
\hline $\begin{array}{l}\text { Orthosiphon stamineus } \\
\text { Benth. }\end{array}$ & $\begin{array}{l}\text { rutin, carnosolic acid, } \\
\text { caffeic acid, } \\
\text { rosmarinic acid, } \\
\text { quercetin, luteolin, } \\
\text { apigenin and } \\
\text { cinnamnic acid }\end{array}$ & $\begin{array}{l}50 \mathrm{mM} \text { borate } \\
\text { buffer (pH 9.0) }\end{array}$ & $\begin{array}{c}\text { UV } \\
(200 \mathrm{~nm})\end{array}$ & $\begin{array}{c}0.053,0.053, \\
0.046,0.040 \\
0.040,0.030 \\
0.023 \text { and } \\
0.020\end{array}$ & $\begin{array}{l}\text { large volume } \\
\text { sample } \\
\text { stacking with } \\
\text { polarity } \\
\text { switching }\end{array}$ & [32] \\
\hline $\begin{array}{l}\text { Peganum harmala semen } \\
\text { infusions }\end{array}$ & $\begin{array}{c}\text { harmine, harmaline, } \\
\text { harmol, harmalol, } \\
\text { harmane, and } \\
\text { norharmane }\end{array}$ & $\begin{array}{l}50 \mathrm{mM} \text { tris }-\mathrm{HCl} \\
(\mathrm{pH} 7.8) \text { with } 20 \% \\
(v / v) \text { of methanol }\end{array}$ & $\begin{array}{c}\text { UV } \\
(254 \mathrm{~nm})\end{array}$ & $0.1-8.3$ & & [79] \\
\hline $\begin{array}{l}\text { Penicillium glaucum, } P . \\
\text { tenuifolium, } \\
\text { P. dubium and P. fugax } \\
\text { fruits }\end{array}$ & $\begin{array}{l}\text { morphine, codeine } \\
\text { and thebaine }\end{array}$ & $\begin{array}{l}100 \mathrm{mM} \text { sodium } \\
\text { phosphate buffer, } \\
\text { containing } 5 \mathrm{mM} \\
\alpha-\mathrm{CD}(\mathrm{pH} 3.0)\end{array}$ & UV (214) & 2.0 & $\begin{array}{l}\text { Ultrasound- } \\
\text { assisted } \\
\text { extraction }\end{array}$ & [80] \\
\hline $\begin{array}{c}\text { Phellodendri } \\
\text { chinensis cortex }\end{array}$ & $\begin{array}{l}\text { berberine, palmatine } \\
\text { and jatrorrhizine }\end{array}$ & $\begin{array}{c}20 \text { mM phosphate } \\
\text { buffer with } \\
\text { methanol } 10 \% \\
(v / v),(\text { pH } 7.0)\end{array}$ & UV & 0.3 & $\begin{array}{l}\text { imprinted } \\
\text { solid-phase } \\
\text { microextrac- } \\
\text { tion }\end{array}$ & [81] \\
\hline $\begin{array}{c}\text { Pholia magra (Cordia } \\
\text { ecalyculata vell, } 500 \\
\text { mg/capsule), Persea } \\
\text { americana and Cyperus } \\
\text { rotundus }\end{array}$ & $\begin{array}{c}\mathrm{NH}_{4}^{+}, \mathrm{K}^{+}, \mathrm{Ca}^{2+}, \mathrm{Na}^{+}, \\
\mathrm{Mg}^{2+}, \mathrm{Mn}^{2+}, \mathrm{Tl}^{3+}, \\
\mathrm{Cr}^{3+}, \mathrm{Pb}^{2+}, \mathrm{Cd}^{2+}, \\
\mathrm{Zn}^{2+}, \mathrm{Cu}^{2+}, \mathrm{Co}^{2+}, \text { and } \\
\mathrm{Ni}^{2+}\end{array}$ & $\begin{array}{c}30 \mathrm{mM} \\
\text { 2-N-MES } \\
\text { /histidine, } \\
1.5 \mathrm{mM} \\
\text { 18-crown-6 ether, } \\
\text { and } 1 \mathrm{mM} \text { citric } \\
\text { acid ( } \mathrm{pH} 6.0 \text { ) }\end{array}$ & $C^{4} D$ & $\begin{array}{c}0.093,0.182, \\
0.405,0.475 \\
0.077,0.170 \\
1.478,0.988 \\
2.008,1.749 \\
0.454,1.193 \\
0.817 \text { and } \\
0.632\end{array}$ & & [82] \\
\hline
\end{tabular}


Table 1. Cont.

\begin{tabular}{|c|c|c|c|c|c|c|}
\hline Sample & Analytes & BGE & Detection & $\begin{array}{c}\mathrm{LOQ} \\
\left(\mu \mathrm{g} \mathrm{mL^{-1 }}\right)\end{array}$ & Remarks & Ref. \\
\hline Phyllanthus urinaria & $\begin{array}{l}\text { rutin, quercetin, } \\
\text { ferulic acid, caffeic } \\
\text { acid, and gallic acid }\end{array}$ & $\begin{array}{l}10 \mathrm{mM} \text { borate } \\
\text { buffer ( } \mathrm{pH} 9.0 \text { ) }\end{array}$ & AM & $\begin{array}{c}\text { nd, } \\
\text { LOD-3.36, } \\
0.45,0.097 \\
0.072 \text { and } \\
1.00\end{array}$ & & [83] \\
\hline Plumula nelumbinis & $\begin{array}{l}\text { neferine, liensinine, } \\
\text { isoliensinine, rutin } \\
\text { and hyperoside }\end{array}$ & $\begin{array}{c}50 \mathrm{mM} \text { borate } \\
\text { buffer (pH 9.2) }\end{array}$ & $\mathrm{AM}$ & $\begin{array}{l}0.42,0.31 \\
0.38,0.35 \\
\text { and } 0.39\end{array}$ & $\begin{array}{l}\text { far infrared- } \\
\text { assisted } \\
\text { solvent } \\
\text { removal }\end{array}$ & [84] \\
\hline $\begin{array}{l}\text { Portulaca oleracea L., } \\
\text { Crataegus pinnatifida } \\
\text { and Aloe vera L. }\end{array}$ & $\begin{array}{l}\text { linolenic acid, lauric } \\
\text { acid, p-coumaric } \\
\text { acid, ascorbic acid, } \\
\text { benzoic acid, caffeic } \\
\text { acid, succinic acid, } \\
\text { and fumaric acid }\end{array}$ & $\begin{array}{c}40 \mathrm{mM} \\
\mathrm{H}_{3} \mathrm{BO}_{3}-40 \mathrm{mM} \\
\mathrm{Na}_{2} \mathrm{~B}_{4} \mathrm{O}_{7} \\
(\mathrm{pH} 8.70)\end{array}$ & $\begin{array}{c}\text { UV } \\
(200 \mathrm{~nm})\end{array}$ & $\begin{array}{l}\text { nd, LOD: } \\
0.02-3.44\end{array}$ & $\begin{array}{c}\text { field } \\
\text { enhancement } \\
\text { sample } \\
\text { stacking for }\end{array}$ & [85] \\
\hline propolis & $\begin{array}{l}\text { pinocembrine; ferulic } \\
\text { acid; p-coumaric } \\
\text { acid; quercetin; and } \\
\text { caffeic acid }\end{array}$ & $\begin{array}{c}100 \mathrm{mM} \text { borate } \\
\text { buffer }(\mathrm{pH}=8.7)\end{array}$ & $\mathrm{EC}$ & $\begin{array}{l}\text { nd, LOD: } \\
0.1-0.5\end{array}$ & & [13] \\
\hline Puerariae radix & $\begin{array}{c}\text { 3'-methoxypuerarin, } \\
\text { puerarin, } \\
\text { 3'-hydroxypuerarin, } \\
\text { ononin, daidzin, } \\
\text { daid-zein and } \\
\text { genistin }\end{array}$ & $\begin{array}{l}35 \text { mM sodium } \\
\text { tetraborate, } \\
9.0 \mathrm{mM} \\
\text { sulfobutylether- } \\
\beta-\mathrm{CD} \\
\alpha \text {-cyclodextrin } \\
\text { (pH9.34) }\end{array}$ & $\begin{array}{c}\text { UV } \\
(254 \mathrm{~nm})\end{array}$ & $2.5-9.5$ & & [86] \\
\hline
\end{tabular}

caffeic acid, isochlorogenic acid

$\mathrm{A}$, isochlorogenic acid $B$, isochlorogenic

Reduning injection acid $\mathrm{C}$, chlorogenic acid, neochlorogenic acid and

cryptochlorogenic acid

$20 \mathrm{mM} \mathrm{NaH}_{2} \mathrm{PO}_{4}$, $10 \mathrm{mM} \beta-\mathrm{CD}$ and $5 \%$ ACN (pH 4.2)

UV $(325 \mathrm{~nm})$

$0.8-1.5$

DPPH-CEDAD
Rhodiola

salidroside and tyrosol
$50 \mathrm{mM}$ borate buffer (pH 9.8)
AM

a novel
graphene/poly
(urea-
formalde-
hyde)
composite
modified
electrode as a
sensitive am-
perometric
detector

UV

(205 nm)
$30 \mathrm{mM}$ borax
solution with (pH 10.5)

0.72 and

0.39
Rourea minor stems bergenin derivatives

(new natural products) 
Table 1. Cont.

\begin{tabular}{|c|c|c|c|c|c|c|}
\hline Sample & Analytes & BGE & Detection & $\begin{array}{c}\mathrm{LOQ} \\
\left(\mu \mathrm{g} \mathrm{mL^{-1 } )}\right.\end{array}$ & Remarks & Ref. \\
\hline $\begin{array}{c}\text { Salvia miltiorrhiza, } S . \\
\text { przewalskii, } \\
\text { S. castanea and } \\
\text { Danshen }\end{array}$ & $\begin{array}{c}\text { protocatechuic } \\
\text { aldehyde, salvianolic } \\
\text { acid C, rosmarinic } \\
\text { acid, salvianolic acid } \\
\text { A, danshensu, } \\
\text { salvianolic acid B and } \\
\text { protocatechuic acid }\end{array}$ & $\begin{array}{l}20 \text { mM sodium } \\
\text { tetraborate } \\
(\mathrm{pH} \mathrm{9.0)}\end{array}$ & $\begin{array}{c}\text { UV } \\
(280 \mathrm{~nm})\end{array}$ & $0.47-1.19$ & & [90] \\
\hline $\begin{array}{l}\text { Sappan Lignum (the } \\
\text { dried heartwood of } \\
\text { Caesalpinia sappan } \\
\text { L,methanolic extract) }\end{array}$ & $\begin{array}{c}\text { brazilin and } \\
\text { protosappanin B }\end{array}$ & $\begin{array}{l}20 \mathrm{mM} \text { borate } \\
\text { buffer containing } \\
6 \% v / v \text { of } \\
\text { methanol } \\
\text { (pH 9.2) }\end{array}$ & $\begin{array}{c}\text { UV } \\
(254 \mathrm{~nm})\end{array}$ & $\begin{array}{l}0.28 \text { and } \\
0.15\end{array}$ & $\begin{array}{l}\text { online } \\
\text { concentration } \\
\text { with acid } \\
\text { barrage } \\
\text { stacking }\end{array}$ & [91] \\
\hline $\begin{array}{c}\text { Scutellariae barbata } \\
\text { extract }\end{array}$ & $\begin{array}{l}\text { baicalein, baicalin, } \\
\text { and quercetin }\end{array}$ & $\begin{array}{c}0.1 \mathrm{M} \text { borate } \\
\text { buffer (pH 9.0) }\end{array}$ & $\mathrm{EC}$ & $<0.22$ & & [92] \\
\hline $\begin{array}{l}\text { Shuxuening } \\
\text { Injection }\end{array}$ & $\begin{array}{c}\text { clitorin, rutin, } \\
\text { isoquercitrin, } \\
\text { quercetin-3-O-D- } \\
\text { glucosyl]-(1-2)-L- } \\
\text { rhamnoside, } \\
\text { kaempferol-3-O- } \\
\text { rutinoside, } \\
\text { kaempferol-7-O- } \beta- \\
\text { D-glucopyranoside, } \\
\text { apigenin-7-O- } \\
\text { Glucoside, } \\
\text { quercetin-3-O-[2-O- } \\
\text { (6-O-p-hydroxyl-E- } \\
\text { coumaroyl)-D- } \\
\text { glucosyl]-(1-2)-L- } \\
\text { rhamnoside, } \\
\text { 3-O-\{2-O-[6-O-(p- } \\
\text { hydroxyl-E- } \\
\text { coumaroyl)- } \\
\text { glucosyl]\}-(1-2) } \\
\text { rhamnosyl } \\
\text { kaempfero }\end{array}$ & $\begin{array}{c}20 \mathrm{mM} \text { phosphate } \\
5 \mathrm{mM} \\
\beta-\text { cyclodextrin } \\
(\beta-\mathrm{CD}), 40 \mathrm{mM} \\
\text { sodium dodecyl } \\
\text { sulfate and } 7.5 \% \\
\text { ACN } \\
\text { (pH 7.0) }\end{array}$ & $\begin{array}{l}\text { UV-VIS (360 } \\
\text { and } 405 \mathrm{~nm})\end{array}$ & $0.04-0.09$ & $\begin{array}{l}\text { On-line } 2,2^{\prime}- \\
\text { Azinobis-(3- } \\
\text { ethylbenzthiazo- } \\
\text { line-6- } \\
\text { sulphonate)- } \\
\text { ccapillary } \\
\text { electrophoresis- } \\
\text { diode array } \\
\text { detector }\end{array}$ & [93] \\
\hline Sophora flavescens & $\begin{array}{c}\text { cytisine, } \\
\text { sophocarpine, } \\
\text { matrine, sophoridine, } \\
\text { and oxymatrine }\end{array}$ & $\begin{array}{c}110 \mathrm{mM} \\
\text { monosodium } \\
\text { phosphate } \\
\text { isopropanol } \\
(85: 15, v / v) \\
(\mathrm{pH} 3.0)\end{array}$ & $\begin{array}{c}\text { UV } \\
(214 \mathrm{~nm})\end{array}$ & $\begin{array}{c}\text { nd, LOD: } \\
0.0004- \\
0.0013\end{array}$ & $\begin{array}{l}\text { subcritical } \\
\text { water } \\
\text { extraction } \\
\text { and field } \\
\text { amplified } \\
\text { sample } \\
\text { stacking }\end{array}$ & [94] \\
\hline $\begin{array}{l}\text { Sophora flavescens } \\
\text { (extract from the dried } \\
\text { root) }\end{array}$ & $\begin{array}{l}\text { matrine, oxymatrine, } \\
\text { and sophoridine }\end{array}$ & $\begin{array}{c}50 \mathrm{mM} \text { sodium } \\
\text { tetraborate } \\
\text { solution, } 500 \mathrm{mM} \\
\text { boric acid and } \\
1.2 \mathrm{mM} \text { citric acid } \\
\text { (pH 7.98) }\end{array}$ & $\begin{array}{c}\text { UV } \\
(210 \mathrm{~nm})\end{array}$ & 60-100 & & [36] \\
\hline
\end{tabular}


Table 1. Cont.

\begin{tabular}{|c|c|c|c|c|c|c|}
\hline Sample & Analytes & BGE & Detection & $\begin{array}{c}\mathrm{LOQ} \\
\left(\mu \mathrm{g} \mathrm{mL^{-1 } )}\right.\end{array}$ & Remarks & Ref. \\
\hline $\begin{array}{l}\text { Swertia mussotii Franch } \\
\text { and preparations } \\
\text { (herbs, granular, } \\
\text { capsules) }\end{array}$ & $\begin{array}{l}\text { oleanolic acid, ursolic } \\
\text { acid, quercetin, and } \\
\text { apigenin }\end{array}$ & $\begin{array}{l}50 \mathrm{mM} \text { borate- } \\
\text { phosphate buffer } \\
\text { with } 5.0 \times 10^{-3} \\
\text { mol L }{ }^{-1} \\
\beta-\text { cyclodextrin } \\
\text { (pH 9.5) }\end{array}$ & $\begin{array}{c}\text { UV } \\
(250 \mathrm{~nm})\end{array}$ & $\begin{array}{c}0.6829 \\
0.4007 \\
0.0124 \text { and } \\
0.5076\end{array}$ & & [95] \\
\hline $\begin{array}{l}\text { thyme and parsley } \\
\text { extracts }\end{array}$ & luteolin and apigenin & $\begin{array}{l}20 \text { mM borate } \\
\text { buffer and } \\
\text { methanol } \\
(90: 10, v / v) \\
(\mathrm{pH} 10.0)\end{array}$ & $\begin{array}{c}\text { UV } \\
(210 \mathrm{~nm})\end{array}$ & $\begin{array}{l}2.98 \text { and } \\
1.41\end{array}$ & & [96] \\
\hline $\begin{array}{l}\text { traditional Chinese } \\
\text { medicines, Hippophae } \\
\text { rhamnoides, Hypericum } \\
\text { perforatum, and } \\
\text { Cacumen platycladi }\end{array}$ & $\begin{array}{l}\text { rutin, quercetrin, } \\
\text { quercetin, } \\
\text { kaempferol, } \\
\text { kaempferide, } \\
\text { catechin, apigenin } \\
\text { and luteolin }\end{array}$ & $\begin{array}{l}18 \text { mM borate } \\
\text { buffer (pH 10.2) }\end{array}$ & $\mathrm{AM}$ & $\begin{array}{c}0.28,0.22 \\
0.26,0.24 \\
0.24,0.22 \\
0.15 \text { and } \\
0.17\end{array}$ & & [97] \\
\hline Trichilia catigua & $\begin{array}{l}\text { epicatechin and } \\
\text { procyanidin B2 }\end{array}$ & $\begin{array}{l}80 \mathrm{mM} \text { borate } \\
\text { buffer with } 2- \\
\text { hydroxypropyl- } \\
\beta \text {-cyclodextrin } \\
10 \mathrm{mMol} \mathrm{L}^{-1} \\
(\mathrm{pH} 8.80)\end{array}$ & $\begin{array}{c}\text { UV } \\
(214 \mathrm{~nm})\end{array}$ & $\begin{array}{l}17.16 \text { and } \\
15.26\end{array}$ & $\begin{array}{l}\text { CE method } \\
\text { faster, more } \\
\text { efficient, less } \\
\text { expensive, } \\
\text { less } \\
\text { polluting than } \\
\text { previously } \\
\text { developed } \\
\text { HPLC } \\
\text { method }\end{array}$ & [98] \\
\hline $\begin{array}{c}\text { Trifolium alexandrinum } \\
\text { seed }\end{array}$ & $\begin{array}{l}\text { soyasaponin I, } \\
\text { azukisaponin } \mathrm{V}, \\
\text { bersimoside I } \\
\text { and bersimoside }\end{array}$ & $\begin{array}{c}80 \mathrm{mM} \text { borate } \\
\text { buffer containing } \\
24 \mathrm{mM} \\
\beta-\mathrm{CD}(\mathrm{pH} 10)\end{array}$ & $\begin{array}{c}\text { UV } \\
(195 \mathrm{~nm})\end{array}$ & $\begin{array}{l}23.33,21.64 \\
23.30 \text { and } \\
22.94\end{array}$ & $\begin{array}{l}\text { diastereomeric } \\
\text { separation in }\end{array}$ & [99] \\
\hline $\begin{array}{l}\text { Urceola rosea leaf } \\
\text { extracts }\end{array}$ & $\begin{array}{l}\text { five phenolic } \\
\text { compounds }\end{array}$ & $\begin{array}{l}25 \text { mM sodium } \\
\text { tetraborate } \\
\text { decahydrate } \\
\text { solution with } \\
\text { (pH 8.5) }\end{array}$ & $\begin{array}{c}\text { UV } \\
(254 \mathrm{~nm})\end{array}$ & 10.9-20.8 & $\begin{array}{l}\text { CE method } \\
\text { was well } \\
\text { comparable to } \\
\text { HPLC }\end{array}$ & [100] \\
\hline $\begin{array}{c}\text { Valeriana officinalis } \\
\text { extracts }\end{array}$ & $\begin{array}{c}\text { acacetin, diosmetin, } \\
\text { chlorogenic acid, } \\
\text { kaempferol, apienin, } \\
\text { luteolin, } \\
\text { p-hydrox-benzoic } \\
\text { acid } \\
\text { and caffeic acid }\end{array}$ & $\begin{array}{l}60 \mathrm{mM} \text { borate } \\
\text { buffer (pH 9.2) }\end{array}$ & AM & $0.033-0.4$ & & [101] \\
\hline $\begin{array}{c}\text { Yansuan Xiaobojian } \\
\text { Pian (berberine tablets), } \\
\text { and plant samples: } \\
\text { Goldthread, Amor } \\
\text { Cork Tree, Goldenseal, } \\
\text { Plantain, Tree Tumeric, } \\
\text { Yellow Root, } \\
\text { Bupleurum and } \\
\text { Oregon Grape }\end{array}$ & berberine & $\begin{array}{c}20 \mathrm{mM} \text { acetic } \\
\text { acid, } 35 \mathrm{mM} \\
2-\mathrm{HP}-\beta-\mathrm{CD} \text {, and } \\
20 \% \text { methanol } \\
\text { (pH 5.0) }\end{array}$ & LIF & $\begin{array}{l}\text { nd, LOD: } \\
0.016\end{array}$ & & [102] \\
\hline
\end{tabular}


Table 1. Cont.

\begin{tabular}{|c|c|c|c|c|c|c|}
\hline Sample & Analytes & BGE & Detection & $\begin{array}{c}\text { LOQ } \\
\left(\mu \mathrm{g} \mathrm{mL}^{-1}\right)\end{array}$ & Remarks & Ref. \\
\hline Yinqiaojiedu tablet & $\begin{array}{l}\text { liquiritin, chlorogenic } \\
\text { acid, and glycyrrhizic } \\
\text { acid }\end{array}$ & $\begin{array}{c}103.1 \mathrm{mM} \text { boric } \\
\text { acid, } 51.6 \mathrm{mM} \\
\text { sodium borate, } \\
9.8 \mathrm{mM} \text { disodium } \\
\text { hydrogen } \\
\text { phosphate, and } \\
\text { 15.6 mM sodium } \\
\text { dihydrogen } \\
\text { phosphate } \\
\text { (pH 7.86) }\end{array}$ & $\begin{array}{c}\text { UV } \\
(254 \mathrm{~nm})\end{array}$ & $\begin{array}{c}0.41,0.79 \\
\text { and } 0.68\end{array}$ & & [103] \\
\hline
\end{tabular}

nd - no data, LOQ - limit of quantification, LOD—limit of detection, $\mathrm{CM}-$ conductometric, $\beta-\mathrm{CD}-\beta$-cyclodextrin, LIF-Laser Induced Fluorescence, Tris—tris(hydroxymethyl)aminomethane, ECL-electrochemiluminescence, AM-amperometric, UV—LEDIF-ultraviolet light-emitting diode-induced native fluorescence, PBS—-sodium phosphate buffer solution, NED-N-(1-naphthyl)ethylenediamine dihydrochloride, SDS—sodium dodecyl sulfate, CL—chemiluminescence, SPE-solid phase extraction, MES-morpholinoethanesulfonic acid, ACN—acetonitrile, capacitively coupled, $\mathrm{C}^{4} \mathrm{D}$ - contactless conductivity, DPPH—1,1-diphenyl-2-picryl-hydrazyl, DAD—diode array detector, $2-\mathrm{HP}-\beta-\mathrm{CD}$-(2-hydroxypropyl)- $\beta$-cyclodextrin.

\subsection{Micellar Electrokinetic Chromatography (MEKC)}

MEKC is a powerful electrophoresis-driven separation technique, which offers good selectivity, high efficiency, optimization flexibility, and significantly reduces organic solvent consumption during its operation. However, it is not possible to avoid organic solvent consumption when MEKC is applied to the analysis of medicinal plant materials or pharmaceutical formulations. This technique allows for the resolution of both neutral and charged compounds and may be applied for the analysis of a broad selection of active constituents; for instance, flavonoids in herbal raw material. The running buffer in MEKC is fortified with surfactants at a concentration exceeding their critical micelle concentration, that leads to forming micelles. The micelles arrange for a pseudostationary phase that enables the differential separating of analyzed compounds as a result of the influence of dispersed surfactants [101]. In reported studies, various pseudostationary phases were introduced. There are four major classes of surfactants: anionic, cationic, zwitterionic, and nonionic [104]. However, anionic surfactant, i.e., sodium dodecyl sulfate, was most frequently used in reported analyses. For more details see Table 2.

In the past decade, MEKC was employed for the separation and quantification of different classes of secondary metabolites in plant extracts among others: coumarins, tanshinones, phenolic acids, terpenoids, iridoids, phenylethanoid glycosydes, phenylpropanoids, and flavonoids, saponin (see Table 2).

The compounds were detected and quantification was achieved mainly by UV absorption, but amperometric detection was also applied (see Table 2).

Recent studies confirm the high separation efficiency of MEKC and indicate tremendous potential for a wide range of analytical applications. Yang et al. employed polyvinylpyrrolidonestabilized graphene-modified MEKC for the separation of tanshinones. The established method was successfully employed for the quality assessment of Danshentong capsules [105]. Cao et al. in turn used MEKC to resolve a mixture of flavonoids, phenolic acids, and saponin. In order to alter the electrophoretic behavior of analytes and to develop the resolution, they added ionic liquids-coated multi-walled carbon nanotubes to the running buffer, which influenced the partitioning of the analytes. Their results give real hope for the future analysis of complex samples based on considerable advantages in overcoming the effects of matrix-induced interferences exhibited in the study [106].

In the case of the use of large amounts of solvents, Chang and coworkers, in their paper, exhibited the elaboration of surfactant-assisted pressurized liquid extraction (PLE) for the effective extraction of flavonoids in Costus speciosus flowers prior to MEKC analysis. The reported work confirmed numerous advantages of PLE, i.e., short extraction time, 
simplicity, efficiency, automation, and environmental friendliness (organic-free). The PLCMEKC approach enabled fast, eco-friendly, and effective extraction and assay of flavonoids in the abovementioned raw material [107].

In terms of improving the detection sensitivity in MEKC, a study by Chang et al. is reported, where the authors elaborated a magnetic iron oxide nanoparticle-based solidphase extraction process in conjunction with the online concentration and separation of salicylic acid in in tobacco leaves through micellar electrokinetic chromatography-UV detection. The authors observed an approximately 1026-fold improvement in the detection sensitivity of the elaborated method in comparison to a single MEKC method without an online concentration [108].

Qualitative and quantitative methods based on MEKC are rapid, efficient, and ecofriendly, and are successfully employed for the routine quality control of herbal drugs and raw plant material (see Table 2).

Table 2. Application of micellar electrokinetic chromatography and microemulsion electrokinetic chromatography.

\begin{tabular}{|c|c|c|c|c|c|c|}
\hline Sample & Analytes & BGE & Detection & $\begin{array}{c}\mathrm{LOQ} \\
\left(\mu \mathrm{g} \mathrm{mL^{-1 }}\right)\end{array}$ & Remarks & Ref. \\
\hline $\begin{array}{l}\text { Calendula officinalis, } \\
\text { Hypericum } \\
\text { perforatum, } \\
\text { Galium verum and } \\
\text { Origanum vulgare } \\
\text { extracts }\end{array}$ & $\begin{array}{c}(+) \text {-catechin, } \\
(-) \text {-epigallocatechin, } \\
(-) \text {-epigallocatechin } \\
\text { gallate, } \\
(-) \text {-epicatechin } \\
\text { gallate and } \\
(-) \text {-epicatechin }\end{array}$ & $\begin{array}{c}10 \mathrm{mM} \mathrm{KH}_{2} \mathrm{PO}_{4} \text { and } \\
8.3 \mathrm{mM} \text { sodium } \\
\text { tetraborate buffer } \\
\text { with } 66.7 \mathrm{mM} \mathrm{SDS}, \\
(\mathrm{pH} 7.0)\end{array}$ & $\begin{array}{c}\text { UV } \\
(210 \mathrm{~nm})\end{array}$ & $0.010-0 / 047$ & $\begin{array}{l}\mathrm{LOD} / \mathrm{LOQ} \\
\mathrm{ng} \mathrm{mL}\end{array}$ & [109] \\
\hline $\begin{array}{l}\text { clove oil, litsea } \\
\text { cubeba oil, and } \\
\text { citronella oil }\end{array}$ & $\begin{array}{l}\text { citronellal, citral (Z; } \\
\text { E), a-pinene, } \\
\text { limonene, linalool, } \\
\text { and eugenol }\end{array}$ & $\begin{array}{c}20 \text { m borate buffer, } \\
50 \text { mMSDS, } 20 \% \\
\text { (v:v), } \\
\text { (pH 9.5) }\end{array}$ & $\begin{array}{c}\text { UV } \\
(210 \mathrm{~nm})\end{array}$ & $0.8-5.9$ & & [110] \\
\hline $\begin{array}{c}\text { Costus speciosus flos } \\
\text { extract }\end{array}$ & $\begin{array}{c}\text { rutin, quercitrin, and } \\
\text { quercetin }\end{array}$ & $\begin{array}{c}10 \text { mM phosphate, } \\
10 \text { mM borate, } \\
50 \text { mM SDS (pH 8.5) }\end{array}$ & $\begin{array}{c}\text { UV } \\
(370 \mathrm{~nm})\end{array}$ & $\begin{array}{l}2.30,1.57 \\
\text { and } 1.07\end{array}$ & $\begin{array}{l}\text { surfactant- } \\
\text { assisted } \\
\text { pressurized } \\
\text { liquid } \\
\text { extraction }\end{array}$ & [107] \\
\hline $\begin{array}{l}\text { Curcuma wenyujin } \\
\text { origin's Chinese } \\
\text { herbal medicines }\end{array}$ & $\begin{array}{l}\text { curdine, curcumenol, } \\
\text { germacrone, } \\
\text { furanodiene, and } \\
\beta \text {-elemene }\end{array}$ & $\begin{array}{c}1.3 \% \text { SDS, } 5.0 \% \\
\text { 1-butanol, } 0.5 \% \text { ethyl } \\
\text { acetate and } 10 \% \\
\text { acetonitrile in } 10 \mathrm{mM} \\
\text { borate buffer (pH 9.0) }\end{array}$ & $\begin{array}{c}\text { UV } \\
(215 \mathrm{~nm})\end{array}$ & $16.0-78.0$ & $\begin{array}{l}\text { MSPD } \\
\text { extraction } \\
\text { coupled } \\
\text { with } \\
\text { MEEKC }\end{array}$ & [111] \\
\hline $\begin{array}{c}\text { Danshentong } \\
\text { capsule } \\
\text { (Salvia miltiorrhiza) }\end{array}$ & $\begin{array}{l}\text { tanshinone IIB, } \\
\text { dihydrotanshinone I, } \\
\text { tanshinone I, } \\
\text { cryptotanshinone, } \\
1,2- \\
\text { dihydrotanshinone I, } \\
\text { miltirone, and } \\
\text { tanshinone IIA }\end{array}$ & $\begin{array}{l}10 \mathrm{mM} \text { borate buffer } \\
\text { (pH 9.3) containing } \\
30 \mathrm{mM} \text { SDS, } 10 \% v / v \\
\text { 2-propanol and } 6 \mu \mathrm{g} \\
\mathrm{mL}^{-1} \text { graphene }\end{array}$ & $\begin{array}{c}\text { UV } \\
(260 \mathrm{~nm})\end{array}$ & 8.73-19.10 & & [105] \\
\hline $\begin{array}{l}\text { Hemidesmus indicus } \\
\text { radix }\end{array}$ & $\begin{array}{l}\text { 2-hydroxy-4- } \\
\text { methoxybenzaldehyde, } \\
\text { 2-hydroxy-4- } \\
\text { methoxybenzoic acid, } \\
\text { and 3-hydroxy-4- } \\
\text { methoxybenzaldehyde }\end{array}$ & $\begin{array}{l}50 \mathrm{mM} \text { phosphate } \\
\text { buffer with } 65 \mathrm{mM} \text { of } \\
\text { sodium } \\
\text { taurodeoxycholate } \\
\text { (pH 2.5) }\end{array}$ & $\begin{array}{c}\text { UV } \\
(254 \mathrm{~nm})\end{array}$ & $\begin{array}{l}0.40,2.5 \\
\text { and } 0.7\end{array}$ & $\begin{array}{c}\text { MEKC } \\
\text { results } \\
\text { confirmed } \\
\text { by } \\
\text { HPLC-MS }\end{array}$ & [112] \\
\hline
\end{tabular}


Table 2. Cont.

\begin{tabular}{|c|c|c|c|c|c|c|}
\hline Sample & Analytes & BGE & Detection & $\begin{array}{c}\mathrm{LOQ} \\
\left(\mu \mathrm{g} \mathrm{mL}^{-1}\right)\end{array}$ & Remarks & Ref. \\
\hline $\begin{array}{c}\text { Heracleum } \\
\text { sphondylium herb } \\
\text { and Aesculus } \\
\text { hippocastanum } \\
\text { cortex }\end{array}$ & $\begin{array}{c}\text { coumarin, scoparone, } \\
\text { isoscopoletin, esculin, } \\
\text { esculetin, } \\
\text { umbelliferone, } \\
\text { xanthotoxin, } \\
\text { byakangelicin, } \\
\text { isopimpinellin, } \\
\text { bergapten, } \\
\text { phellopterin, } \\
\text { xanthotoxol }\end{array}$ & $\begin{array}{l}50 \mathrm{mM} \text { sodium } \\
\text { tetraborate, } 45 \mathrm{mM} \\
\mathrm{SC} \text {, and } 20 \% \text { of } \\
\text { methanol }(v / v) \\
(\mathrm{pH} 9.00)\end{array}$ & $\begin{array}{c}\text { UV } \\
(214 \mathrm{~nm})\end{array}$ & $1.70-4.772$ & & [113] \\
\hline He-Shou-Wu & $\begin{array}{l}\text { hypohorine, THSG, } \\
\text { epicatechin, } \\
\text { proanthocyanidin B2, } \\
\text { proantocyanidin B1, } \\
\text { catechin and gallic } \\
\text { acid }\end{array}$ & $\begin{array}{c}50 \mathrm{mM} \text { phosphate } \\
\text { buffer containing } \\
90 \mathrm{mM} \text { SDS and } 2 \% \\
(\mathrm{~m} / \mathrm{v}) \mathrm{HP}-\beta-\mathrm{CD} \\
(\mathrm{pH} 2.5)\end{array}$ & $\begin{array}{c}\text { UV } \\
(210 \mathrm{~nm})\end{array}$ & $<5.5$ & $\begin{array}{l}\text { pressurized } \\
\text { liquid } \\
\text { extraction } \\
\text { and } \\
\text { short-end } \\
\text { injection } \\
\text { MEKC }\end{array}$ & [114] \\
\hline $\begin{array}{l}\text { Larrea divaricata Cav. } \\
\text { extracts }\end{array}$ & $\begin{array}{l}\text { nordihydroguaiaretic } \\
\text { acid }\end{array}$ & $\begin{array}{c}20 \mathrm{mM} \text { phosphate } \\
\text { buffer } 10 \mathrm{mM} \text { SDS } \\
\text { and } 10 \% \text { acetonitrile, } \\
(\mathrm{pH} 7.5)\end{array}$ & $\begin{array}{c}\text { UV } \\
(283 \mathrm{~nm})\end{array}$ & 1.06 & & [115] \\
\hline Lianqiao Baidu pill & $\begin{array}{l}\text { genistein, caffeic acid, } \\
\text { glycyrrhizic acid } \\
\text { ammonium salt, } \\
\text { wogonoside }\end{array}$ & $\begin{array}{l}30 \mathrm{mMol} \mathrm{L}^{-1} \mathrm{SB}, \\
95 \mathrm{mMol} \mathrm{L} \\
\text { and } 100 \mathrm{mMol} \mathrm{L}^{-1} \\
\text { boric acid (pH 9.30) }\end{array}$ & $\begin{array}{c}\text { UV } \\
(214 \mathrm{~nm})\end{array}$ & $0.77-1.85$ & & [116] \\
\hline $\begin{array}{l}\text { Ligaria cuneifolia } \\
\text { extracts }\end{array}$ & $\begin{array}{l}\text { catechin, epicatechin, } \\
\text { procyanidin } \mathrm{B} 2, \text { rutin, } \\
\text { quercetin-3-O- } \\
\text { glucoside, } \\
\text { quercetin-3-O- } \\
\text { xyloside, } \\
\text { quercetin-3-O- } \\
\text { rhamnoside, } \\
\text { quercetin-3-O- } \\
\text { arabinofuranoside, } \\
\text { quercetin-3-O- } \\
\text { arabinopyranoside } \\
\text { and quercetin }\end{array}$ & $\begin{array}{c}20 \mathrm{mM} \text { borate buffer, } \\
50 \mathrm{mM} \text { SDS } \mathrm{mM} \\
\beta-\mathrm{CD} \text { and } 2 \% w / v \\
\text { S- } \beta-\mathrm{CD} \text { and } 10 \% v / v \\
\text { methanol } \\
(\mathrm{pH} 8.3)\end{array}$ & $\begin{array}{c}\text { UV } \\
\text { (255 and } \\
280 \mathrm{~nm})\end{array}$ & $0.26-1.33$ & & [117] \\
\hline Lippia alba leaves & $\begin{array}{l}\text { genoposidic acid, } \\
\text { 8-epi-loganin, } \\
\text { mussaenoside, } \\
\text { chrysoeriol-7-O- } \\
\text { diglucuronide, } \\
\text { triclin-7-O- } \\
\text { diglucuronide, } \\
\text { acetoside }\end{array}$ & $\begin{array}{c}50 \mathrm{mM} \text { borax buffer } \\
\text { containing } 75 \mathrm{mM} \\
\text { SDS and } 5 \% \\
\text { isopropanol }\end{array}$ & & $38.0-119.0$ & $\begin{array}{c}\text { no } \\
\text { statistically } \\
\text { singificant } \\
\text { differences } \\
\text { beetween } \\
\text { CE and } \\
\text { HPLC }\end{array}$ & [118] \\
\hline
\end{tabular}


Table 2. Cont.

\begin{tabular}{|c|c|c|c|c|c|c|}
\hline Sample & Analytes & BGE & Detection & $\begin{array}{c}\mathrm{LOQ} \\
\left(\mu \mathrm{g} \mathrm{mL^{-1 } )}\right.\end{array}$ & Remarks & Ref. \\
\hline $\begin{array}{c}\text { Nicotiana tabacum L. } \\
\text { leaves }\end{array}$ & salicylic acid & $\begin{array}{l}\text { TB buffer containing } \\
100 \mathrm{mM} \text { SDS and } 15 \% \\
(v / v) \text { acetonitrile } \\
(\mathrm{pH} 10.0)\end{array}$ & $\begin{array}{c}\text { UV } \\
(205 \mathrm{~nm})\end{array}$ & $\begin{array}{l}\text { nd, LOD: } \\
0.0005\end{array}$ & $\begin{array}{c}\text { magnetic } \\
\text { iron oxide } \\
\text { nanoparticle- } \\
\text { based } \\
\text { solid-phase } \\
\text { extraction } \\
\text { procedure } \\
\text { followed by } \\
\text { an online } \\
\text { concentra- } \\
\text { tion } \\
\text { technique }\end{array}$ & [108] \\
\hline
\end{tabular}

\section{Petroselinum crispum,}

Rosmarinus officinalis,

Thymus vulgaris L.,

Origanum vulgare,

Origanum majorana

L., Salvia officinalis

L., and Levisticum officinale

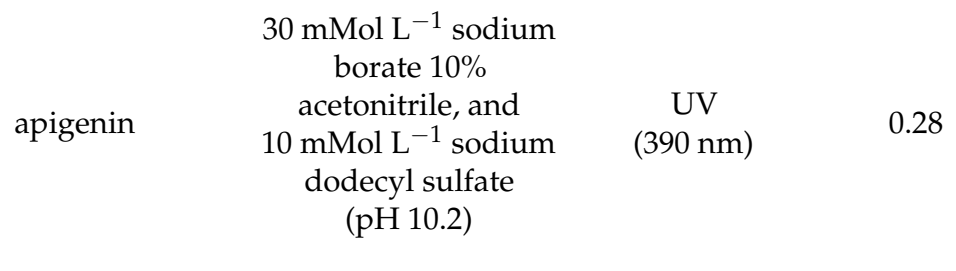

$30 \mathrm{mMol} \mathrm{L}^{-1}$ sodium

borate $10 \%$

odecyl sulfate
Plantago lanceolata,

Plantago major, and

Plantago asiatica leaf extracts and

biotechnological product, plant tissue cultures (calli) of $P$. lanceolata.

aucubin, catalpol, verbascoside and plantamajoside
$15 \mathrm{mM}$ sodium tetraborate, $20 \mathrm{mM}$ TAPS and $250 \mathrm{mM}$ DOC (pH 8.50)

$\begin{array}{cc}\text { UV } & 1360,1630, \\ (200 \text { and } & 2350 \text { and } \\ 350 \mathrm{~nm}) & 2720\end{array}$

[119]

\begin{tabular}{|c|c|c|c|c|c|c|}
\hline $\begin{array}{l}\text { Qishenyiqi } \\
\text { dropping pills }\end{array}$ & $\begin{array}{c}\text { calycosin-7-O- } \beta-\mathrm{D}- \\
\text { glucoside, } \\
\text { formononetin, } \\
\text { dihydroquercetin, } \\
\text { rosmarinic acid, } \\
\text { danshensu, } \\
\text { salvianolic acid } \mathrm{B}, \\
\text { protocatechuic acid, } \\
\text { ginsenoside } \mathrm{Rg}_{1}, \\
\text { ginsenoside } \mathrm{Rb}_{1}\end{array}$ & $\begin{array}{c}10 \mathrm{mM} \text { borate buffer } \\
\text { (pH 9.0) containing } \\
100 \mathrm{mM} \text { SDS, } 6 \% \\
\text { propanol and } 4 \mu \mathrm{g} \\
\mathrm{mL}^{-1} \\
\text { ILs-MWNTs }\end{array}$ & $\begin{array}{c}\text { UV } \\
(200 \mathrm{~nm})\end{array}$ & $\begin{array}{l}\text { nd, LOD: } \\
1.01-76.32\end{array}$ & $\begin{array}{l}\text { ionic liquids } \\
\text { coated } \\
\text { multi- } \\
\text { walled } \\
\text { carbon } \\
\text { nanotubes } \\
\text { as pseudo- } \\
\text { stationary } \\
\text { phase }\end{array}$ & [106] \\
\hline $\begin{array}{l}\text { Salvia chionantha } \\
\text { and Salvia } \\
\text { kronenburgii } \\
\text { acetone extracts }\end{array}$ & $\begin{array}{l}\text { horminone and } 7-\mathrm{O}- \\
\text { acetylhorminone }\end{array}$ & $\begin{array}{l}50 \text { mM SDS, 25\% } \\
\text { metanol (pH:11.5) }\end{array}$ & $\begin{array}{c}\text { UV } \\
(230 \mathrm{~nm})\end{array}$ & $\begin{array}{l}\text { nd, LOD: } \\
3.269 \text { and } \\
4.518\end{array}$ & & [121] \\
\hline $\begin{array}{l}\text { Salvia miltiorrhiza, S. } \\
\text { przewalskii, and } S . \\
\text { castanea }\end{array}$ & $\begin{array}{l}\text { dihydrotanshinone I, } \\
\text { cryptotanshinone, } \\
\text { protocatechuic } \\
\text { aldehyde, tanshinone } \\
\text { I, tanshinone Ila, } \\
\text { salvianolic acid C, } \\
\text { rosmarinic acid, } \\
9^{\prime} \text {-methyl } \\
\text { lithospermate b, } \\
\text { danshensu, salvianolic } \\
\text { acid B and } \\
\text { protocatechuic acid }\end{array}$ & $\begin{array}{c}15 \mathrm{mM} \text { sodium } \\
\text { tetraborate with } \\
10 \mathrm{mM} \text { SDS, } 5 \mathrm{mM} \\
\beta-\mathrm{CD}, 10 \mathrm{mM} \\
{\left[\mathrm{bmim} \mathrm{BF}_{4} \text { and } 15 \%\right.} \\
\mathrm{ACN}(v / v),(\mathrm{pH} 9.8)\end{array}$ & $\begin{array}{c}\text { UV } \\
(254 \mathrm{~nm})\end{array}$ & $0.90-4.63$ & & [122] \\
\hline
\end{tabular}


Table 2. Cont.

\begin{tabular}{|c|c|c|c|c|c|c|}
\hline Sample & Analytes & BGE & Detection & $\begin{array}{c}\text { LOQ } \\
\left(\mu \mathrm{g} \mathrm{mL}^{-1}\right)\end{array}$ & Remarks & Ref. \\
\hline $\begin{array}{l}\text { Schisandra } \\
\text { chinensis }\end{array}$ & $\begin{array}{l}\text { schizandrin, } \\
\text { schisandrol B, } \\
\text { schisantherin B, } \\
\text { schisantherin A, } \\
\text { schisanhenol, } \\
\text { deoxyschizandrin, } \\
\text { schisandrin B }\end{array}$ & $\begin{array}{c}35 \mathrm{mM} \text { phosphate } \\
\text { with } 10 \mathrm{mM} \\
\beta \text {-cyclodextrin } \\
(\beta-\mathrm{CD}) \\
30 \mathrm{mM} \text { sodium } \\
\text { dodecyl sulfate (SDS) } \\
\text { and } 10 \% \text { ACN } \\
(\mathrm{pH} 8.0)\end{array}$ & $\begin{array}{c}\text { UV } \\
(222 \mathrm{~nm})\end{array}$ & $0.02-0.12$ & $\begin{array}{l}2,2- \\
\text { azinobis-(3- } \\
\text { ethylbenzoth- } \\
\text { iazoline-6- } \\
\text { sulfonic } \\
\text { acid)- } \\
\text { sweeping } \\
\text { micellar } \\
\text { electroki- } \\
\text { netic } \\
\text { chromato- } \\
\text { graphy- } \\
\text { diode array } \\
\text { detector }\end{array}$ & [123] \\
\hline
\end{tabular}

nd—no data, LOQ—limit of quantification, LOD—limit of detection, SDS—sodium dodecyl sulfate, SB—sodium borate, MSPD—micro matrix solid phase dispersion, TAPS- $-\mathrm{N}-[(1 \mathrm{~S}, 2 \mathrm{~S}, 3 \mathrm{R})-2,3-$ bis(acetyloxy)-1-[(acetyloxy)methyl]heptadecyl]-acetamide, DOC-anionic detergents sodium deoxycholate, ILs-MWNTs-ionic liquids coated multi-walled carbon nanotubes, $\beta-\mathrm{CD}-\beta-$ cyclodextrin, HP- $\beta-\mathrm{CD}-$ hydroxypropyl- $\beta$-cyclodextrin, THSG-2,3,5,4'-tetrahydroxystilbene $2-O-\beta-$ D-glucoside, SC—sodium cholate.

\subsection{Non-Aqueous Capillary Electrophoresis}

Non-aqueous capillary electrophoresis (NACE) is a potent alternative to aqueous electrophoretic techniques, especially when it is difficult to separate lipophilic compounds. Separation of analytes is achieved using non-aqueous background electrolytes and the principle is based on the diverse physical and chemical properties of organic solvents. This great variety of solvents broadens the scope of separation selectivity. The low generation of current in nonaqueous media allows the use of high electric field strengths and wide bore capillaries and subsequentially allows a larger volume of the sample. Other advantages of NACE include better solubility of analytes in organic solvents, MS compatibility, and finally enhanced detection selectivity in many cases [124]. Analogically to the CZE sample, preconcentration techniques are applied in order to develop detection sensitivity in NACE. Field-amplified sample stacking, large-volume stacking using the electroosmotic flow pump, and transient isotachophoresis proved to be suitable for the abovementioned purpose and not only in aqueous CE. What is more, employment of LVSEP for NACE allowed the sensitive determination of organic anions at the nanomolar range using conventional UV detection and the introduction of ITP shortened the time of analysis [41].

The non-aqueous approach is not as prevalent as CZE or MEKC, but literature analysis indicates some applications for the analysis of herbal drugs and plant material. This technique was used in the study published by Hou et al. for the efficient separation and determination of five alkaloids in Coptidis rhizoma. In this work, surfactant-coated multi-walled carbon nanotubes provided a pseudostationary phase. Numerous parameters affecting NACE separation were studied, and in consequence, the authors noticed an important enhancement in the resolution due to the $\pi-\pi$ interactions between the analyzed compounds and the surface of the carbon nanotubes in comparison to conventional NACE [125]. Meanwhile, Yuan et al. proposed a fast and uncomplicated method for the analysis of atropine, anisodamine, and scopolamine in Deturae flos extract by NACE coupled with electrochemiluminescence and electrochemistry dual detection. The running buffer was composed of acetonitrile and 2-propanol containing $1 \mathrm{M}$ acetic acid, $20 \mathrm{mM}$ sodium acetate, and $2.5 \mathrm{mM}$ tetrabutylammonium perchlorate. Despite using a short capillary of $18 \mathrm{~cm}$, the decoupler was not necessary and the separation performance was respectable [126]. Dresler et at. analyzed lipophilic compounds (hypericin and hyperforin) in Hypericum extracts with the non-aqueous capillary electrophoresis. The separation of the abovementioned constituents was conducted using bare fused silica $75 \mu \mathrm{m}$ i.d. capillaries with an effective total length of $80.0 \mathrm{~cm}$. The running buffer was a mixture of 
methanol, dimethylsulfoxide, and N-methyl formamide (3:2:1 $v / v / v)$ as a solvent, with $50 \mathrm{mM}$ ammonium acetate, $150 \mathrm{mM}$ sodium acetate, and $0.02 \%(w / v)$ of cationic polymer hexadimethrine bromide to reverse the flow. At the same time, flavonoids and chlorogenic were evaluated with traditional $\mathrm{CE}$ as described above (Section 2.2). Only non-significant statistical differences were observed between the HPLC and CE results, namely the average differences between the particular metabolite ranged, e.g., from less than $10 \%$ for rutin and hypericin to ca. $1 \%$ for quercitrin [35]. The NACE method was also optimized for the simultaneous determination of major bioactive curcuminoids and some of the degradation products in turmeric milk and herbal commercial products. Non-aqueous BGE for separation of analytes was composed of sodium tetraborate, sodium hydroxide, methanol, and 1-propanol. Moreover, an innovative ultrasonication-assisted phase separation method was optimized and employed for extraction of the analytes in turmeric milk and subsequent direct injection of the extract into the capillary without any pretreatment [12]. The abovementioned NACE methods are simple, fast, convenient, and economical and applicable to analysis of herb extracts and commercial products (see Table 3).

Table 3. Application of nonaqueous capillary electrophoresis.

\begin{tabular}{|c|c|c|c|c|c|c|}
\hline Sample & Analytes & BGE & Detection & $\begin{array}{c}\mathrm{LOQ} \\
\left(\mu \mathrm{g} \mathrm{mL}^{-1}\right)\end{array}$ & Remarks & Ref. \\
\hline Coptidis rhizoma & $\begin{array}{l}\text { coptisin, } \\
\text { berberine, } \\
\text { epiberberine, } \\
\text { palmatine, } \\
\text { jatrorrizine }\end{array}$ & $\begin{array}{c}20 \mathrm{mM} \text { sodium acetate in } \\
\text { methanol-acetonitrile } \\
(80: 20, v / v), 20 \% \\
\text { acetonitrile and } \\
6 \mu \mathrm{g} \mathrm{mL}{ }^{-1} \mathrm{SC}-\mathrm{MWNTs}\end{array}$ & $\begin{array}{c}\text { UV } \\
(254 \mathrm{~nm})\end{array}$ & $0.31-0.34$ & & [125] \\
\hline $\begin{array}{l}\text { Daturae flos } \\
\text { extract }\end{array}$ & $\begin{array}{l}\text { atropine, } \\
\text { anisodamine, } \\
\text { and } \\
\text { scopolamine }\end{array}$ & $\begin{array}{c}\text { acetonitrile and } \\
\text { 2-propanol containing } \\
1 \mathrm{M} \text { acetic acid, } 20 \mathrm{mM} \\
\text { sodium acetate and } \\
2.5 \mathrm{mM} \\
\text { tetrabutylammonium } \\
\text { perchlorate }\end{array}$ & $\begin{array}{l}\text { ECL and EC } \\
\text { dual detection }\end{array}$ & $0.5-50.0$ & & [126] \\
\hline $\begin{array}{l}\text { Hypericum } \\
\text { perforatum and } \\
\text { Hypericum } \\
\text { annulatum }\end{array}$ & $\begin{array}{l}\text { hypericin and } \\
\text { hyperfolin }\end{array}$ & $\begin{array}{c}\text { methanol, } \\
\text { dimethylsulfoxide, } \\
\mathrm{N}-\text { methyl formamide } \\
(3: 2: 1 \mathrm{v} / \mathrm{v} / \mathrm{v}) \text { with } 50 \mathrm{mM} \\
\text { ammonium acetate, } \\
150 \mathrm{mM} \text { sodium acetate } \\
\text { and } 0.02 \%(w / v) \text { of } \\
\text { cationic polymer } \\
\text { hexadimethrine bromide }\end{array}$ & $\begin{array}{c}\text { UV } \\
\text { (294 and 594) }\end{array}$ & $\begin{array}{c}2.191-2.948 \\
\text { ppm }\end{array}$ & & [35] \\
\hline $\begin{array}{l}\text { Turmeric milk } \\
\text { (Curcuma longa) } \\
\text { and herbal } \\
\text { products }\end{array}$ & $\begin{array}{l}\text { curcumin, } \\
\text { desmethoxycur- } \\
\text { cumin and } \\
\text { bisdesmethoxy- } \\
\text { curcumin, } \\
\text { vanillin, vanillic } \\
\text { acid, ferulic } \\
\text { acid, and } \\
\text { 4-hydroxyben- } \\
\text { zaldehyde }\end{array}$ & $\begin{array}{l}\text { a mixture of sodium } \\
\text { tetraborate, sodium } \\
\text { hydroxide, methanol } \\
\text { and 1-propanol }\end{array}$ & $\begin{array}{l}\text { UV-VIS } \\
\text { (300 and } \\
498 \mathrm{~nm})\end{array}$ & $10.1-26.5$ & $\begin{array}{c}\text { a novel } \\
\text { ultrasonication- } \\
\text { assisted phase } \\
\text { separation } \\
\text { method } \\
\text { (US-PS) was } \\
\text { used for } \\
\text { extraction and } \\
\text { subsequently } \\
\text { the extract was } \\
\text { directly injected } \\
\text { into the } \\
\text { capillary }\end{array}$ & [12] \\
\hline
\end{tabular}

nd-no data, LOQ—-limit of quantification, LOD—limit of detection, SC-MWNTs—surfactant-coated multi-walled carbon nanotubes, ECL—electrochemiluminescence, EC—electrochemistry. 


\subsection{Capillary Electrochromatography (CEC)}

Capillary electrochromatography is a hybrid technique because it merges features of both high performance liquid chromatography and capillary electrophoresis and may be applied for the determination of charged and neutral analytes. In $\mathrm{CE}$, analytes are separated in a capillary column with electroosmotic flow as the driving force for bulk fluid movement. However, in capillary electrochromatography, the capillary contains a stationary phase as in HPLC. Hence, there is a capability to take advantage of different mechanisms to provide additional selectivity beyond that possible through HPLC or CE alone. This combination of $\mathrm{CE}$ has advantages, i.e., high-efficiency, low-solvent and sample consumption, and reverse-phase mechanism of HPLC makes this technique reliable and flexible and, what is more, it can be fully suitable for pharmaceutical analysis and can replace other more demanding techniques in terms of time and expenses $[127,128]$. On the other hand, in comparison to CZE, the optimization of CEC is more challenging, the efficiency is lower due to peak broadening and the reproducibility of retention times is poorer [129]. However, a continuous fulfilling CEC with nanoparticles as a pseudostationary phase coupled with MS detection demonstrates high separation efficiency, as well as high performance confirmed by such parameters as limit of detection, peak asymmetry, repeatability, and reproducibility [130]. Except for employing a detector with high sensitivity, other approaches to achieve good detection sensitivity, as well as resolution and separation efficiency, include bubble or Z-type cells to extend the optical path, and obviously sample preconcentration techniques. For instance, FASS and in-column detection $[131,132]$. CEC was reported for the fast separation and quantification of coumarins in Angelica dahurica extract. A methacrylate ester-based monolithic column was used as a stationary phase. In order to gain a significant raise in the selectivity, surfactant sodium desoxycholate was added to the mobile phase as the pseudostationary, so there was no need to increase the hydrophobicity of the stationary phase. The devised method was characterized not only by satisfactory separation and a running time of $6 \mathrm{~min}$, but also by LOQs lower than $0.30 \mu \mathrm{g} / \mathrm{mL}^{-1}$ [133]. The second reported study describes a CEC method for the quality control of Cnidii fructus extracts. This method, taking advantage of the methacrylate esterbased monolithic column, was characterized by an acceptable resolution of LOQs between 1.0 and $2.8 \mu \mathrm{g} / \mathrm{mL}^{-1}$ and the time of operation was shortened to $5 \mathrm{~min}$ [134]. For more details see Table 4 .

Table 4. Application of capillary electrochromatography.

\begin{tabular}{|c|c|c|c|c|c|c|}
\hline Sample & Analytes & BGE & Detection & $\begin{array}{c}\mathrm{LOQ} \\
\left(\mu \mathrm{g} \mathrm{mL^{-1 } )}\right.\end{array}$ & Remarks & Ref. \\
\hline $\begin{array}{c}\text { Angelica dahurica } \\
\text { extract }\end{array}$ & $\begin{array}{c}\text { byakangelicin, } \\
\text { oxypeucedanin } \\
\text { hydrate, } \\
\text { xanthotoxol, } \\
\text { 5-hydroxy-8- } \\
\text { methoxypsoralen } \\
\text { and bergapten }\end{array}$ & $\begin{array}{c}30: 70 \mathrm{v} / v \\
\text { ACN-buffer } \\
\text { containing } 20 \mathrm{mM} \\
\text { sodium dihydrogen } \\
\text { phosphate } \\
\left(\mathrm{NaH}_{2} \mathrm{PO}_{4}\right) \text { and } \\
0.25 \mathrm{mM} \mathrm{SDC} \\
(\mathrm{pH} 2.51)\end{array}$ & $\begin{array}{c}\text { UV } \\
(210 \mathrm{~nm})\end{array}$ & $<0.30$ & $\begin{array}{l}\text { methacrylate } \\
\text { ester-based } \\
\text { monolithic } \\
\text { column }\end{array}$ & [133] \\
\hline $\begin{array}{l}\text { Cnidii fructus } \\
\text { extracts }\end{array}$ & $\begin{array}{l}\text { isopimpinelline, } \\
\text { bergapten, } \\
\text { imperatorin and } \\
\text { osthole }\end{array}$ & $\begin{array}{l}50 \% \text { ACN and } 50 \% \\
\text { of a } 10 \text { mM sodium } \\
\text { dihydrogen } \\
\text { phosphate } \\
\text { (pH 4.95) }\end{array}$ & $\begin{array}{c}\text { UV } \\
(210 \mathrm{~nm})\end{array}$ & $1.0-2.8$ & $\begin{array}{l}\text { poly(butyl } \\
\text { methacrylate-co- } \\
\text { ethylene } \\
\text { dimethacrylate- } \\
\text { co-[2-(metha- } \\
\text { cryloyloxy)ethyl] } \\
\text { trimethylammo- } \\
\text { nium chloride) } \\
\text { monolithic } \\
\text { column }\end{array}$ & [134] \\
\hline
\end{tabular}




\subsection{Capillary Electrophoresis-Mass Spectrometry (CE-MS)}

Capillary electrophoresis has many advantages in HPLC (low solvent consumption, using inexpensive capillaries, short time of operation, high efficiency without sample retreatment) and can support complementary or supplementary information about the constitution of a sample. One of the limitations of CE techniques is the relatively poor sensitivity as a result of the injection of small sample volumes, which might be improved by the implementation of pre-concentration techniques. The other way is to take advantage of CE-MS hyphenation, which not only enhances LOD thanks to MS detection, but also allows for the measurement of the particular mass of analytes and offers structural information, including the opportunity to identify and determine co-migrating species in overlapping peaks [135]. In reported papers, authors have described the quantitative analysis mainly of alkaloid compounds in plant extracts/pharmaceutical formulations.

In the study of Liu et al., the CEC-MS method, fully applicable for the quality evaluation of Evodiae fructus, was elaborated. It should be underlined that 4-16 fold improvement of detection limits was achieved in comparison to the CEC method with conventional UV detection [136]. Wang et al. proposed matrix solid-phase dispersion microextraction combined with $\mathrm{CE}$ in conjunction with quadrupole time-of-flight mass spectrometry for the quantification of three alkaloids in Fritillariae Thunbergii bulbus. It is noteworthy that in this method the reported LOQ value is in the $\mathrm{ng} \mathrm{mL}^{-1}$ level [137]. All reported CE-MS methods were effectively employed for qualitative and quantitative analysis of bioactive components in plant extract and pharmaceutical preparations (see Table 5).

Table 5. Application of capillary electrophoresis with MS detection.

\begin{tabular}{|c|c|c|c|c|c|c|}
\hline Sample & Analytes & BGE & Method & $\begin{array}{c}\mathrm{LOQ} \\
\left(\mu \mathrm{g} \mathrm{mL^{-1 } )}\right.\end{array}$ & Remarks & Ref. \\
\hline $\begin{array}{c}\text { Catharanthus } \\
\text { roseus }\end{array}$ & $\begin{array}{c}\text { vinblastine, } \\
\text { vindoline, and } \\
\text { catharanthine }\end{array}$ & $\begin{array}{c}20 \mathrm{mM} \text { ammonium } \\
\text { acetate and } 1.5 \% \\
\text { acetic acid }\end{array}$ & CE-MS & $\begin{array}{l}\text { nd, LOD: } \\
0.1-0.8\end{array}$ & & [135] \\
\hline Evodiae fructus & $\begin{array}{l}\text { limonin, } \\
\text { evodiamine, and } \\
\text { rutaecarpine }\end{array}$ & $\begin{array}{c}30 \% \text { acetonitrile } \\
\text { (ACN) in } 1 \% \\
\text { ammonia aqueous } \\
\text { solution }\end{array}$ & CEC-MS & $\begin{array}{c}3.1,0.63 \text { and } \\
0.15\end{array}$ & $\begin{array}{l}\text { provided } 4-16 \text { folds } \\
\text { improvement of } \\
\text { LODs when } \\
\text { compared with } \\
\text { CEC-UV method }\end{array}$ & [136] \\
\hline $\begin{array}{c}\text { Fritillariae } \\
\text { Thunbergii bulbus }\end{array}$ & $\begin{array}{l}\text { peimine, } \\
\text { peiminine, and } \\
\text { peimisine }\end{array}$ & $\begin{array}{c}20 \mathrm{mM} \text { ammonium } \\
\text { acetate } \\
\text { with MS-grade } \\
\text { water }\end{array}$ & $\begin{array}{c}\text { CE-Q-TOF- } \\
\text { MS }\end{array}$ & $0.004-0.005$ & $\begin{array}{c}\text { solid acids } \\
\text { assisted matrix } \\
\text { solid-phase } \\
\text { dispersion } \\
\text { micro-extraction }\end{array}$ & [137] \\
\hline $\begin{array}{l}\text { Lycoris radiata } \\
\text { roots }\end{array}$ & $\begin{array}{c}\text { lycorine, } \\
\text { lycoramine, } \\
\text { lycoremine, } \\
\text { lycobetaine, and } \\
\text { dihydrolycorine }\end{array}$ & $\begin{array}{c}\text { ACN and methanol } \\
(1: 2, v / v), \text { which } \\
40 \mathrm{mM} \text { ammonium } \\
\text { acetate and } \\
0.5 \% \text { acetic acid }\end{array}$ & $\begin{array}{c}\text { NACE } \\
\text { ESI-IT-MS }\end{array}$ & $0.04-0.24$ & & [138] \\
\hline $\begin{array}{l}\text { Psoralae fructus } \\
\text { and } \\
\text { pharmaceutical } \\
\text { preparations }\end{array}$ & $\begin{array}{c}\text { bavachin and } \\
\text { isobavachalcone }\end{array}$ & $\begin{array}{c}20 \text { mM aqueous } \\
\text { solution of } \\
\text { ammonium acetate } \\
\text { (pH 10.0) }\end{array}$ & CE-ESI-MS & nd, LOD: 0.06 & & [139] \\
\hline $\begin{array}{c}\text { Banisteriopsis } \\
\text { caapi, Datura } \\
\text { stramonium, } \\
\text { Mimosa tenuiflora, } \\
\text { Peganum harmala, } \\
\text { Voacanga africana, } \\
\text { Ayahuasca }\end{array}$ & $\begin{array}{c}\text { harmaline, } \\
\text { harmine, } \\
\text { harmalol, } \\
\text { norharmane, } \\
\text { harmane, harmol, } \\
\text { tetrahydro- } \\
\text { harmine, and } \\
\text { tryptamine }\end{array}$ & $\begin{array}{l}58 \mathrm{mMol} \mathrm{L}^{-1} \\
\text { ammonium } \\
\text { formate and } 1.01 \\
\text { mol } \mathrm{L}^{-1} \text { acetic acid } \\
\text { in acetonitrile }\end{array}$ & NACE-MS & $\begin{array}{c}0.01,0.01, \\
0.015,0.012, \\
0.018,0.019, \\
0.022 \text { and } \\
0.024\end{array}$ & & [140] \\
\hline
\end{tabular}


Table 5. Cont.

\begin{tabular}{|c|c|c|c|c|c|c|}
\hline Sample & Analytes & BGE & Method & $\begin{array}{c}\mathrm{LOQ} \\
\left(\mu \mathrm{g} \mathrm{mL}^{-1}\right)\end{array}$ & Remarks & Ref. \\
\hline $\begin{array}{c}\text { Rheum (Rhubarb, } \\
\text { Dahuang) } \\
\text { extracts }\end{array}$ & $\begin{array}{c}\text { physcion, } \\
\text { chrysophanol, } \\
\text { and aloe-emodin }\end{array}$ & $\begin{array}{l}80 \% \text { methanol and } \\
20 \% \text { acetonitrile } \\
\text { with } \\
20 \text { mM ammonium } \\
\text { acetate }\end{array}$ & $\begin{array}{c}\text { NACE-ESI- } \\
\text { MS/MS }\end{array}$ & $\begin{array}{c}\text { nd, LOD: } 84 \\
180 \text { and } 210 \\
\text { ppb }\end{array}$ & & [141] \\
\hline $\begin{array}{c}\text { Stephaniae } \\
\text { tetrandrae radix } \\
\text { and Menispermum } \\
\text { dauricum rhizoma }\end{array}$ & $\begin{array}{c}\text { tetrandrine, } \\
\text { fangchinoline, } \\
\text { and sinomenine }\end{array}$ & $\begin{array}{c}80 \mathrm{mM} \text { solution of } \\
\text { ammonium acetate } \\
\text { with mixture of } \\
70 \% \text { methanol, } 20 \% \\
\mathrm{ACN} \text {, and } 10 \% \\
\text { water, which also } \\
\text { contained } 1 \% \text { acetic } \\
\text { acid }\end{array}$ & $\begin{array}{c}\text { NACE-IT- } \\
\text { MS }\end{array}$ & $\begin{array}{c}\text { nd, LOD: } 0.05 \text {, } \\
0.08 \text {, and } 0.15\end{array}$ & & [142] \\
\hline Tinosporae radix & $\begin{array}{l}\text { palmatine, } \\
\text { cepharanthine, } \\
\text { menisperine, } \\
\text { magnoflorine, } \\
\text { columbin and } \\
\text { 20-hydroxy- } \\
\text { ecdysone }\end{array}$ & $\begin{array}{c}\text { methanol and } \\
\text { acetonitrile }(4: 1 ; \\
v / v), \text { which } \\
\text { contained } 40 \text { or } \\
50 \text { mM ammonium } \\
\text { acetate and } 0.5 \% \\
\text { acetic acid }\end{array}$ & $\begin{array}{c}\text { NACE-ESI- } \\
\text { MS }\end{array}$ & $0.06-4.0$ & & [2] \\
\hline
\end{tabular}

nd-no data, CE-Q-TOF-MS-capillary electrophoresis coupled with quadrupole time-of-flight mass spectrometry, ESI-ITMS - electrospray ionization ion trap mass spectrometry, ESI-MS—electrospray ionization mass spectrometry, IT-MS-ion trap mass spectrometry.

\section{Materials and Methods}

The present literature review is based on PRISMA guidelines. The selection criteria for the articles for the review were formulated on the basis of the PICOS process (see Table 6). For the purpose of this review, articles from 2010 to 2019 were taken into consideration. Searching of the literature for this publication was performed between January 2021 and March 2021 using the PubMed and Web of Science databases. The search strategy took place with the use of the following keywords:

1. "capillary electrophoresis" AND

2. "pharmaceutical analysis" OR "determination" OR "quantification" AND

3. "herbal drugs" OR "medicinal plants" OR "plant extracts" OR "plant metabolites".

Table 6. PICOS (Population, Intervention, Comparison, Outcome, Study type).

\begin{tabular}{ccc}
\hline & Inclusion Criteria & Exclusion Criteria \\
\hline Population & herbal drugs and medicinal plants & $\begin{array}{c}\text { garden and ornamental plants, vegetables and } \\
\text { fruits, edible products, beverages }\end{array}$ \\
\hline Intervention & use of CE method & other methods \\
\hline Comparison & $\begin{array}{c}\text { capillary electrophoresis } \\
\text { vs. other methods }\end{array}$ & not applicable \\
\hline Outcome & analysis of active constituents \\
Study type & original research articles, \\
& full articles, English language & different outcomes \\
\hline
\end{tabular}

In the PubMed database, a combination of terms 'All fields' and in Web of Science base terms 'Topic' was used, which searches titles, abstracts, author keywords, keywords, and more. Only articles in English, available full texts and articles delineating the quantitative 
analysis of bioactive components in medicinal plants and pharmaceutical formulations by $\mathrm{CE}$ are included in this review. The exclusion criteria were opinion letters, conferences, abstracts, and papers not written in English (for example, in Chinese). Publications restricted only to fingerprinting or separation without quantitative analysis were rejected. Additionally, articles with urine, human plasma and blood serum, and edible products such as the matrix were eliminated. Studies in which amino acids in plant tissues, enzyme inhibition or alternations of secondary metabolites in plants under different factors analyzed using CE were also not taken into account. Duplicates were removed and found articles were sorted by title, abstract, and then main text. The articles were excluded if they did not meet the inclusion criteria. Selection of appropriate works taking into account the inclusion and exclusion criteria were controlled by the three authors of this paper (M. G., A. P, M. K.) Selection of the publications by them was made on the basis of a qualitative and quantitative evaluation of articles from the PubMed and Web of Science databases, especially by title of paper, first name of the author, and year publication.

\section{Conclusions}

The present review summarized the state of the art applications of capillary electrophoresis over a past decade. The versatile application of CE-based methods was recorded due to the possibility of using different techniques of $\mathrm{CE}$ adapted to the substance to be determined and their numerous modifications.

The present scrutiny reveals a large number of applications, including different formulations, various plant extracts, simultaneous identification, and quantification of even several active constituents in a complex matrix. In the reported works, CZE, MEKC, and NACE were successfully used for the assay of different classes of secondary metabolites, whereas NACE was employed for the analysis of lipophilic compounds, CEC for the analysis of coumarins and CE-MS mainly for alkaloid compounds. Due to its many advantages, such as little solvent and sample consumption, short time of operation, and high efficiency, $\mathrm{CE}$ is an attractive and eco-friendly approach in current pharmaceutical analysis and its continuous development gives hope for well-established, validated, and increasingly accurate and precise methods of quality control of pharmaceutical formulations and herbal raw material.

Among all reported methods, the most common is the CE-UV technique; however, in some cases, resolution and sensitivity are limited. For this reason, other methods of detection, such as conductometry, electrochemiluminescence, laser-induced fluorescence, and hyphenation of CE-MS, have successfully been applied. Moreover, among other electrophoretic techniques, MEKC and NACE are well established. Other ways to solve this problem are through the addition of some modifiers to the BGE, i.e., cyclodextrins are added as a chiral selectors during enantiomeric separation, or through introducing sophisticated extraction and/or pre-concentration techniques. The flexibility of CE is a great advantage, i.e., it includes many opportunities for optimizing the parameters of analysis, additives to BGE, introducing in-line and online preconcentration techniques and different methods of detection, and makes every electrophoretic technique capable of being used for the routine qualitative and quantitative analysis of active constituents in plant material or herbal formulation even at the $\mathrm{ng} \mathrm{mL}^{-1}$ level. In some cases, a comparison of the results obtained with CE to HPLC methods exhibited no statistically significant differences. Moreover, differences in sensitivity are relevant only in the analysis of samples with very low analyte concentrations, which does not directly relate to pharmaceutical analysis, where the content of the active ingredient, for instance in tablets, is at the milligram level. This suggests the CE method may be better where it does not influence the quality of the analysis, because of its shorter time of execution, lower costs, and eco-friendly approach. It should also be noted that the future of $\mathrm{CE}$ is strongly connected to hyphenation with the MS technique because of its ability for both measuring molecular weight and for offering structural information. On the one hand, detection sensitivities of the reported methods based on CE-MS were relatively low, but in some cases, they were comparable to results achieved even with UV 
detection. On the other hand, more and more utilizations of CE-MS, as well as a constant development, indicate that this hyphenation is heading in the right direction.

In conclusion, CE is a powerful analytical tool, and after adequate optimization, it could be an auspicious alternative to more expensive methods in the pharmaceutical quality control of herbal drugs and herbal raw material.

Author Contributions: The article was prepared by all authors. Conceptualization: M.G., A.P.; methodology: M.G., S.K., M.K.; investigation: M.G., A.P., K.M.-G., A.B.; supervision: S.K., M.K.; visualization: A.P., K.M.-G.; writing—original draft: M.G.; writing—review and editing: A.P., K.M.-G., A.B. All authors have read and agreed to the published version of the manuscript.

Funding: This research received no external funding.

Data Availability Statement: All data obtained during the research appears in the submitted article.

Conflicts of Interest: The authors declare no conflict of interest.

\section{References}

1. Barnes, J.; Anderson, L.A.; Phillipson, J.D. Herbal Medicine, 3rd ed.; Pharmaceutical Press: London, UK, 2007.

2. Liu, Y.; Zhou, W.; Mao, Z.; Liao, X.; Chen, Z. Analysis of six active components in Radix tinosporae by nonaqueous capillary electrophoresis with mass spectrometry. J. Sep. Sci. 2017, 40, 4628-4635. [CrossRef] [PubMed]

3. Li, F.; Weng, J. Demystifying traditional herbal medicine with. Nat. Publ. Gr. 2017, 3, 1-7. [CrossRef]

4. Folashade, O.; Omoregie, H.; Ochogu, P. Standardization of herbal medicines-A review. Int. J. Biodivers. Conserv. 2012, 4, 101-112. [CrossRef]

5. European Medicines Agency. The EU regulatory system for medicines. A consistent approach to medicines regulation across the European Union; EMA: London, UK, 2016; pp. 1-6.

6. The FDA's Drug Review Process: Ensuring Drugs Are Safe and Effective. Available online: https://www.fda.gov/drugs/ information-consumers-and-patients-drugs/fdas-drug-review-process-ensuring-drugs-are-safe-and-effective (accessed on 19 March 2021).

7. Viana, C.; Ferreira, M.; Romero, C.S.; Bortoluzzi, M.R.; Lima, F.O.; Rolim, C.M.B.; De Carvalho, L.M. A capillary zone electrophoretic method for the determination of hypoglycemics as adulterants in herbal formulations used for the treatment of diabetes. Anal. Methods 2013, 5, 2126-2133. [CrossRef]

8. Johnson, R.T.; Lunte, C.E. A capillary electrophoresis electrospray ionization-mass spectrometry method using a borate background electrolyte for the fingerprinting analysis of flavonoids in Ginkgo biloba herbal supplements. Anal. Methods 2016, 8, 3325-3332. [CrossRef]

9. Moreira, A.P.L.; Motta, M.J.; Dal Molin, T.R.; Viana, C.; de Carvalho, L.M. Determination of diuretics and laxatives as adulterants in herbal formulations for weight loss. Food Addit. Contam. Part A Chem. Anal. Control. Expo. Risk Assess. 2013, 30, 1230-1237. [CrossRef] [PubMed]

10. Chen, J.; Zhu, H.; Chu, V.M.; Jang, Y.S.; Son, J.Y.; Kim, Y.H.; Son, C.G.; Seol, I.C.; Kang, J.S. Quality control of a herbal medicinal preparation using high-performance liquid chromatographic and capillary electrophoretic methods. J. Pharm. Biomed. Anal. 2011, 55, 206-210. [CrossRef]

11. Feng, A.; Tian, B.; Hu, J.; Zhou, P. Recent Applications of Capillary Electrophoresis in the Analysis of Traditional Chinese Medicines. Comb. Chem. High. Throughput Screen. 2010, 13, 954-965. [CrossRef] [PubMed]

12. Anubala, S.; Sekar, R.; Nagaiah, K. Determination of Curcuminoids and Their Degradation Products in Turmeric (Curcuma longa) Rhizome Herbal Products by Non-aqueous Capillary Electrophoresis with Photodiode Array Detection. Food Anal. Methods 2016, 9, 2567-2578. [CrossRef]

13. Peng, Y.Y. Study on capillary electrophoresis-amperometric detection profiles from propolis and its medicinal preparations. Adv. Mater. Res. 2013, 750-752, 1617-1620. [CrossRef]

14. Tubaon, R.M.S.; Rabanes, H.; Haddad, P.R.; Quirino, J.P. Capillary electrophoresis of natural products: 2011-2012. Electrophoresis 2014, 35, 190-204. [CrossRef]

15. Zalewska, M.; Wilk, K.; Milnerowicz, H. Review capillary electrophoresis application in the analysis of the anti-cancer drugs impurities. Acta Pol. Pharm. Drug Res. Drug Res. 2013, 70, 171-180.

16. Jorgenson, J.W.; DeArman Lukacs, K. Zone electrophoresis in open-tubular glass capillaries: Preliminary data on performance. J. High. Resolut. Chromatogr. 1981, 4, 230-231. [CrossRef]

17. Hurtado-Fernández, E.; Gómez-Romero, M.; Carrasco-Pancorbo, A.; Fernández-Gutiérrez Alberto, A. Application and potential of capillary electroseparation methods to determine antioxidant phenolic compounds from plant food material. J. Pharm. Biomed. Anal. 2010, 53, 1130-1160. [CrossRef] [PubMed]

18. Li, S.F.Y. Chapter 1 Introduction. In Capillary Electrophoresis-Principles, Practice and Applications; Elsevier: Amsterdam, The Netherlands; London, UK; New York, NY, USA; Tokyo, Japan, 1992; pp. 1-30.

19. Altria, K.D. Capillary Electrophoresis Guidebook; Humana Press: Totowa, NJ, USA, 1995; Volume 52, ISBN 0-89603-315-5. 
20. Honegr, J.; Pospíšilová, M. Determination of phenolic acids in plant extracts using CZE with on-line transient isotachophoretic preconcentration. J. Sep. Sci. 2013, 36, 729-735. [CrossRef]

21. Liang, J.; Gong, F.Q.; Sun, H.M. Simultaneous separation of eight lignans in Forsythia suspensa by $\beta$-cyclodextrin-modified capillary zone electrophoresis. Molecules 2018, 23, 514. [CrossRef] [PubMed]

22. Xiao, M.W.; Bai, X.L.; Liu, Y.M.; Yang, L.; Hu, Y.D.; Liao, X. Rapid quantification of aloin A and B in aloe plants and aloe-containing beverages, and pharmaceutical preparations by microchip capillary electrophoresis with laser induced fluorescence detection. $J$. Sep. Sci. 2018, 41, 3772-3781. [CrossRef]

23. Xiang, Q.; Gao, Y.; Han, B.; Li, J.; Xu, Y.; Yin, J. Determination of arecoline in areca nut based on field amplification in capillary electrophoresis coupled with electrochemiluminescence detection. Luminescence 2013, 28, 50-55. [CrossRef] [PubMed]

24. Song, J.Z.; Han, Q.B.; Qiao, C.F.; But, P.P.H.; Xu, H.X. Development and validation of a rapid capillary zone electrophoresis method for the determination of aconite alkaloids in aconite roots. Phytochem. Anal. 2010, 21, 137-143. [CrossRef]

25. de Jong, G. Detection in Capillary Electrophoresis-An Introduction. In Capillary Electrophoresis-Mass Spectrometry (CE-MS): Principles and Applications; Wiley-VCH Verlag GmbH \& Co. KGaA: Weinheim, Germany, 2016; pp. 1-5.

26. Jarvas, G.; Guttman, A.; Miękus, N.; Baczzek, T.; Jeong, S.; Chung, D.S.; Pätoprstý, V.; Masár, M.; Hutta, M.; Datinská, V.; et al. Practical sample pretreatment techniques coupled with capillary electrophoresis for real samples in complex matrices. TrAC-Trends Anal. Chem. 2020, 122, 115702. [CrossRef]

27. Mao, H.; Ye, X.; Chen, W.; Geng, W.; Chen, G. Fabrication of carbon nanotube-polylactic acid composite electrode by melt compounding for capillary electrophoretic determination of tectoridin and irigenin in Belamcandae Rhizoma. J. Pharm. Biomed. Anal. 2019, 175, 112769. [CrossRef]

28. Zhang, L.; Zhang, W.; Chen, G. Determination of arbutin and bergenin in Bergeniae Rhizoma by capillary electrophoresis with a carbon nanotube-epoxy composite electrode. J. Pharm. Biomed. Anal. 2015, 115, 323-329. [CrossRef]

29. Sheng, S.; Liu, S.; Zhang, L.; Chen, G. Graphene/poly(ethylene-co-vinyl acetate) composite electrode fabricated by melt compounding for capillary electrophoretic determination of flavones in Cacumen platycladi. J. Sep. Sci. 2013, 36, 721-728. [CrossRef]

30. Ren, T.; Xu, Z. Study of isomeric pentacyclic triterpene acids in traditional Chinese medicine of Forsythiae Fructus and their binding constants with $\beta$-cyclodextrin by capillary electrophoresis. Electrophoresis 2018, 39, 1006-1013. [CrossRef]

31. Deng, D.; Deng, H.; Zhang, L.; Su, Y. Determination of ephedrine and pseudoephedrine by field-amplified sample injection capillary electrophoresis. J. Chromatogr. Sci. 2014, 52, 357-362. [CrossRef]

32. Honegr, J.; Šafra, J.; Polášek, M.; Pospíšilová, M. Large-volume sample stacking with polarity switching in CE for determination of natural polyphenols in plant extracts. Chromatographia 2010, 72, 885-891. [CrossRef]

33. Magnuszewska, J.; Krogulec, T. Application of hot platinum microelectrodes for determination of flavonoids in flow injection analysis and capillary electrophoresis. Anal. Chim. Acta 2013, 786, 39-46. [CrossRef]

34. Du, J.-X.; Wang, M. Capillary Electrophoresis Determination of Berberine in Pharmaceuticals with End-Column Electrochemiluminescence Detection. J. Chin. Chem. Soc. 2010, 57, 696-700. [CrossRef]

35. Dresler, S.; Kováčik, J.; Strzemski, M.; Sowa, I.; Wójciak-Kosior, M. Methodological aspects of biologically active compounds quantification in the genus Hypericum. J. Pharm. Biomed. Anal. 2018, 155, 82-90. [CrossRef] [PubMed]

36. Hou, Z.; Sun, G.; Guo, Y.; Yang, F.; Gong, D. Capillary Electrophoresis Fingerprints Combined with Linear Quantitative Profiling Method to Monitor the Quality Consistency and Predict the Antioxidant Activity of Alkaloids of Sophora flavescens; Elsevier Ltd.: Amsterdam, The Netherland, 2019; Volume 1133, ISBN 8602423986286.

37. Olabi, M.; Stein, M.; Wätzig, H. Affinity capillary electrophoresis for studying interactions in life sciences. Methods 2018, 146, 76-92. [CrossRef]

38. He, X.; Ding, Y.; Li, D.; Lin, B. Recent advances in the study of biomolecular interactions by capillary electrophoresis. Electrophoresis 2004, 25, 697-711. [CrossRef] [PubMed]

39. Wehr, T. Capillary Zone Electrophoresis. In Encyclopedia of Physical Science and Technology; Elsevier: Amsterdam, The Netherland, 2003; pp. 355-368.

40. Steiner, F.; Hassel, M. Nonaqueous capillary electrophoresis: A versatile completion of electrophoretic separation techniques. Electrophoresis 2000, 21, 3994-4016. [CrossRef]

41. Huie, C.W. Effects of organic solvents on sample pretreatment and separation performances in capillary electrophoresis. Electrophoresis 2003, 24, 1508-1529. [CrossRef]

42. Beckers, J.L.; Ackermans, M.T.; Boček, P. Capillary zone electrophoresis in methanol: Migration behavior and background electrolytes. Electrophoresis 2003, 24, 1544-1552. [CrossRef]

43. Gao, Z.; Zhong, W. Recent (2018-2020) development in capillary electrophoresis. Anal. Bioanal. Chem. 2021. [CrossRef]

44. Xu, L.; Chang, R.; Chen, M.; Li, L.; Huang, Y.; Zhang, H.; Chen, A. Quality evaluation of Guan-Xin-Ning injection based on fingerprint analysis and simultaneous separation and determination of seven bioactive constituents by capillary electrophoresis. Electrophoresis 2017, 38, 3168-3176. [CrossRef] [PubMed]

45. Alzoman, N.Z.; Maher, H.M.; Al-Showiman, H.; Fawzy, G.A.; Al-Taweel, A.M.; Perveen, S.; Tareen, R.B.; Al-Sabbagh, R.M. CE-DAD determination of scutellarein and caffeic acid in Abelia triflora crude extract. J. Chromatogr. Sci. 2018, 56, 746-752. [CrossRef] [PubMed] 
46. Bao, Y.; Yang, F.; Yang, X. CE-electrochemiluminescence with ionic liquid for the facile separation and determination of diesterditerpenoid aconitum alkaloids in traditional Chinese herbal medicine. Electrophoresis 2011, 32, 1515-1521. [CrossRef] [PubMed]

47. Dutra, L.S.; Leite, M.N.; Brandão, M.A.F.; De Almeida, P.A.; Vaz, F.A.S.; De Oliveira, M.A.L. A rapid method for total $\beta-$ escin analysis in dry, hydroalcoholic and hydroglycolic extracts of Aesculus hippocastanum L. by capillary zone electrophoresis. Phytochem. Anal. 2013, 24, 513-519. [CrossRef] [PubMed]

48. Kubrak, T.; Dresler, S.; Szymczak, G.; Bogucka-Kocka, A. Rapid Determination of Coumarins in Plants by Capillary Electrophoresis. Anal. Lett. 2015, 48, 2819-2832. [CrossRef]

49. Chen, M.; Huang, Y.; Xu, L.; Zhang, H.; Zhang, G.; Chen, A. Simultaneous separation and analysis of camptothecin alkaloids in real samples by large-volume sample stacking in capillary electrophoresis. Biomed. Chromatogr. 2018, 32. [CrossRef] [PubMed]

50. Wang, N.; Su, M.; Liang, S.; Sun, H. Investigation of six bioactive anthraquinones in slimming tea by accelerated solvent extraction and high performance capillary electrophoresis with diode-array detection. Food Chem. 2016, 199, 1-7. [CrossRef]

51. Roda, G.; Liberti, V.; Arnoldi, S.; Argo, A.; Rusconi, C.; Suardi, S.; Gambaro, V. Capillary electrophoretic and extraction conditions for the analysis of Catha edulis FORKS active principles. Forensic Sci. Int. 2013, 228, 154-159. [CrossRef]

52. Şanli, S.; Lunte, C. Determination of eleven flavonoids in chamomile and linden extracts by capillary electrophoresis. Anal. Methods 2014, 6, 3858-3864. [CrossRef]

53. Kulp, M.; Bragina, O.; Kogerman, P.; Kaljurand, M. Capillary electrophoresis with led-induced native fluorescence detection for determination of isoquinoline alkaloids and their cytotoxicity in extracts of Chelidonium majus L. J. Chromatogr. A 2011, 1218, 5298-5304. [CrossRef] [PubMed]

54. Zhang, L.; Zhang, W.; Chen, W.; Chen, G. Simultaneous determination of five bioactive constituents in Rhizoma Chuanxiong by capillary electrophoresis with a carbon nanotube-polydimethylsiloxane composite electrode. J. Pharm. Biomed. Anal. 2016, 131, 107-112. [CrossRef]

55. Diop, E.H.A.; Jacquat, J.; Drouin, N.; Queiroz, E.F.; Wolfender, J.L.; Diop, T.; Schappler, J.; Rudaz, S. Quantitative CE analysis of punicalagin in Combretum aculeatum extracts traditionally used in Senegal for the treatment of tuberculosis. Electrophoresis 2019, 40, 2820-2827. [CrossRef]

56. Müller, L.S.; Da Silveira, G.D.; Dal Prá, V.; Lameira, O.; Viana, C.; De Carvalho, L.M. Investigation of phenolic antioxidants as chemical markers in extracts of Connarus perrottetii var. Angustifolius radlk by capillary zone electrophoresis. J. Liq. Chromatogr. Relat. Technol. 2016, 39, 13-20. [CrossRef]

57. Deng, Y.; Lam, S.C.; Zhao, J.; Li, S.P. Quantitative analysis of flavonoids and phenolic acid in Coreopsis tinctoria Nutt. by capillary zone electrophoresis. Electrophoresis 2017, 38, 2654-2661. [CrossRef] [PubMed]

58. Ye, N.; Li, J.; Gao, C.; Xie, Y. Simultaneous determination of atropine, scopolamine, and anisodamine in Flos daturae by capillary electrophoresis using a capillary coated by graphene oxide. J. Sep. Sci. 2013, 36, 2698-2702. [CrossRef]

59. Lü, W.; Li, M.; Chen, Y.; Chen, H.; Chen, X. Simultaneous determination of iridoid glycosides and flavanoids in Lamionphlomis rotate and its herbal preparation by a simple and rapid capillary zone electrophoresis method. Drug Test. Anal. 2012, 4, 123-128. [CrossRef]

60. Dresler, S.; Kubrak, T.; Bogucka-Kocka, A.; Szymczak, G. Determination of shikonin and rosmarinic acid in Echium vulgare L. and Echium russicum J.F. Gmel. by capillary electrophoresis. J. Liq. Chromatogr. Relat. Technol. 2015, 38, 698-701. [CrossRef]

61. Xie, J.P.; Xiang, J.M.; Zhu, Z.L. Determination of Five Major 8-Prenylflavones in Leaves of Epimedium by Solid-Phase Extraction Coupled with Capillary Electrophoresis. J. Chromatogr. Sci. 2016, 54, 664-669. [CrossRef] [PubMed]

62. Yang, X.; Zhang, S.; Wang, J.; Wang, C.; Wang, Z. On-line two-step stacking in capillary zone electrophoresis for the preconcentration of strychnine and brucine. Anal. Chim. Acta 2014, 814, 63-68. [CrossRef]

63. Xia, Y.G.; Liang, J.; Yang, B.Y.; Wang, Q.H.; Kuang, H.X. A new method for quantitative determination of two uronic acids by CZE with direct UV detection. Biomed. Chromatogr. 2011, 25, 1030-1037. [CrossRef] [PubMed]

64. Liu, L.; You, W.; Zheng, L.; Chen, F.; Jia, Z. Determination of peimine and peiminine in Bulbus Fritillariae Thunbergii by capillary electrophoresis by indirect UV detection using N-(1-naphthyl)ethylenediamine dihydrochloride as probe. Electrophoresis 2012, 33, 2152-2158. [CrossRef] [PubMed]

65. Abhijith, B.L.; Mohan, M.; Joseph, D.; Haleema, S.; Aboul-Enein, H.Y.; Ibnusaud, I. Capillary zone electrophorsis for the analysis of naturally occurring 2-hydroxycitric acids and their lactones. J. Sep. Sci. 2017, 40, 3351-3357. [CrossRef]

66. Wang, X.; Li, J.; Qu, W.; Chen, G. Fabrication of graphene/poly(methyl methacrylate) composite electrode for capillary electrophoretic determination of bioactive constituents in Herba geranii. J. Chromatogr. A 2011, 1218, 5542-5548. [CrossRef]

67. Wang, J.; Wang, H.; Han, S. Ultrasensitive determination of epicatechin, rutin, and quercetin by capillary electrophoresis chemiluminescence. Acta Chromatogr. 2012, 24, 679-688. [CrossRef]

68. Chen, H.; Ding, X.; Wang, M.; Chen, X. An automated method of on-line extraction coupled with flow injection and capillary electrophoresis for phytochemical analysis. J. Chromatogr. Sci. 2010, 48, 866-870. [CrossRef] [PubMed]

69. Lu, Y.; Wang, X.; Chen, D.; Chen, G. Polystyrene/graphene composite electrode fabricated by in situ polymerization for capillary electrophoretic determination of bioactive constituents in Herba houttuyniae. Electrophoresis 2011, 32, 1906-1912. [CrossRef]

70. Gao, S.Y.; Li, H.; Wang, L.; Yang, L.N. Simultaneous separation and determination of benzoic acid compounds in the plant medicine by high performance capillary electrophoresis. J. Chin. Chem. Soc. 2010, 57, 1374-1380. [CrossRef]

71. Maráková, K.; Mikuš, P.; Piešt'anský, J.; Havránek, E. Determination of curcuminoids in substances and dosage forms by cyclodextrin-mediated capillary electrophoresis with diode array detection. Chem. Pap. 2011, 65, 398-405. [CrossRef] 
72. Dong, S.; Gao, R.; Yang, Y.; Guo, M.; Ni, J.; Zhao, L. Simultaneous determination of phenylethanoid glycosides and aglycones by capillary zone electrophoresis with running buffer modifier. Anal. Biochem. 2014, 449, 158-163. [CrossRef]

73. Deng, B.; Xie, F.; Li, L.; Shi, A.; Liu, Y.; Yin, H. Determination of galanthamine in Bulbus Lycoridis Radiatae by coupling capillary electrophoresis with end-column electrochemiluminescence detection. J. Sep. Sci. 2010, 33, 2356-2360. [CrossRef]

74. Sun, S.; Wei, Y.; Cao, Y.; Deng, B. Simultaneous electrochemiluminescence determination of galanthamine, homolycorine, lycorenine, and tazettine in Lycoris radiata by capillary electrophoresis with ultrasonic-assisted extraction. J. Chromatogr. B Anal. Technol. Biomed. Life Sci. 2017, 1055-1056, 15-19. [CrossRef] [PubMed]

75. Fu, Y.; Zhang, L.; Chen, G. Determination of carbohydrates in Folium Lysium Chinensis using capillary electrophoresis combined with far-infrared light irradiation-assisted extraction. J. Sep. Sci. 2011, 34, 3272-3278. [CrossRef] [PubMed]

76. Sun, Y.; Li, Y.; Zeng, J.; Lu, Q.; Li, P.C.H. Microchip electrophoretic separation and fluorescence detection of chelerythrine and sanguinarine in medicinal plants. Talanta 2015, 142, 90-96. [CrossRef] [PubMed]

77. Han, P.; Luan, F.; Yan, X.; Gao, Y.; Liu, H. Separation and determination of honokiol and magnolol in Chinese traditional medicines by capillary electrophoresis with the application of response surface methodology and radial basis function neural network. J. Chromatogr. Sci. 2012, 50, 71-75. [CrossRef]

78. Gatea, F.; Teodor, E.D.; Matei, A.O.; Badea, G.I.; Radu, G.L. Capillary Electrophoresis Method for 20 Polyphenols Separation in Propolis and Plant Extracts. Food Anal. Methods 2015, 8, 1197-1206. [CrossRef]

79. Tascón, M.; Benavente, F.; Vizioli, N.M.; Gagliardi, L.G. A rapid and simple method for the determination of psychoactive alkaloids by CE-UV: Application to Peganum Harmala seed infusions. Drug Test. Anal. 2017, 9, 596-602. [CrossRef] [PubMed]

80. Fakhari, A.R.; Nojavan, S.; Ebrahimi, S.N.; Evenhuis, C.J. Optimized ultrasound-assisted extraction procedure for the analysis of opium alkaloids in Papaver plants by cyclodextrin-modified capillary electrophoresis. J. Sep. Sci. 2010, 33, 2153-2159. [CrossRef]

81. Zhang, W.; Li, Y.; Chen, Z. Selective and sensitive determination of protoberberines by capillary electrophoresis coupled with molecularly imprinted microextraction. J. Sep. Sci. 2015, 38, 3969-3975. [CrossRef]

82. de Carvalho, L.M.; Raabe, A.; Martini, M.; Sant'anna, C.S.; da Silveira, G.D.; do Nascimento, P.C.; Bohrer, D. Contactless Conductivity detection of 14 inorganic cations in mineral and phytotherapeutic formulations after capillary electrophoretic separation. Electroanalysis 2011, 23, 2574-2581. [CrossRef]

83. Deng, G.H.; Chen, S.; Wang, H.; Gao, J.; Luo, X.; Huang, H. Determination of active ingredients of Phyllanthus urinaria by capillary electrophoresis with amperometric detection. J. Liq. Chromatogr. Relat. Technol. 2012, 35, 2370-2380. [CrossRef]

84. Wan, D.; Han, Y.; Li, F.; Mao, H.; Chen, G. Far infrared-assisted removal of extraction solvent for capillary electrophoretic determination of the bioactive constituents in Plumula nelumbinis. Electrophoresis 2019, 40, 582-586. [CrossRef] [PubMed]

85. Zhu, Q.; Xu, X.; Huang, Y.; Xu, L.; Chen, G. Field enhancement sample stacking for analysis of organic acids in traditional Chinese medicine by capillary electrophoresis. J. Chromatogr. A 2012, 1246, 35-39. [CrossRef]

86. Guo, J.; Wang, M.; Guo, H.; Chang, R.; Yu, H.; Zhang, G.; Chen, A. Simultaneous separation and determination of seven isoflavones in Radix puerariae by capillary electrophoresis with a dual cyclodextrin system. Biomed. Chromatogr. 2019, 33. [CrossRef]

87. Chang, Y.X.; Liu, J.; Bai, Y.; Li, J.; Liu, E.W.; He, J.; Jiao, X.C.; Wang, Z.Z.; Gao, X.M.; Zhang, B.L.; et al. The activity-integrated method for quality assessment of Reduning injection by on-line DPPH-CE-DAD. PLoS ONE 2014, 9, e106254. [CrossRef]

88. Chen, B.; Zhang, L.; Chen, G. Determination of salidroside and tyrosol in Rhodiola by capillary electrophoresis with graphene/poly(urea-formaldehyde) composite modified electrode. Electrophoresis 2011, 32, 870-876. [CrossRef]

89. Ngoc, H.N.; Löffler, S.; Nghiem, D.T.; Pham, T.L.G.; Stuppner, H.; Ganzera, M. Phytochemical study of Rourea minor stems and the analysis of therein contained Bergenin and Catechin derivatives by capillary electrophoresis. Microchem. J. 2019, 149, 104063. [CrossRef]

90. Cao, J.; We, J.; Tian, K.; Su, H.; Wan, J.; Li, P. Simultaneous determination of seven phenolic acids in three Salvia species by capillary zone electrophoresis with $\beta$-cyclodextrin as modifier. J. Sep. Sci. 2014, 37, 3738-3744. [CrossRef] [PubMed]

91. Lu, Y.; Bai, H.; Kong, C.; Zhong, H.; Breadmore, M.C. Analysis of brazilin and protosappanin B in sappan lignum by capillary zone electrophoresis with acid barrage stacking. Electrophoresis 2013, 34, 3326-3332. [CrossRef] [PubMed]

92. Wang, Y.; Wei, Z.; Zhang, J.; Wang, X. Electrochemical determination of baicalein, baicalin and quercetin in Scutellaria barbata. Int. J. Electrochem. Sci. 2016, 11, 8323-8331. [CrossRef]

93. Ma, H.; Li, J.; An, M.; Gao, X.M.; Chang, Y.X. A powerful on line ABTS+-CE-DAD method to screen and quantify major antioxidants for quality control of Shuxuening Injection. Sci. Rep. 2018, 8, 1-10. [CrossRef] [PubMed]

94. Wang, H.; Lu, Y.; Chen, J.; Li, J.; Liu, S. Subcritical water extraction of alkaloids in Sophora flavescens Ait. and determination by capillary electrophoresis with field-amplified sample stacking. J. Pharm. Biomed. Anal. 2012, 58, 146-151. [CrossRef] [PubMed]

95. Gao, R.; Wang, L.; Yang, Y.; Ni, J.; Zhao, L.; Dong, S.; Guo, M. Simultaneous determination of oleanolic acid, ursolic acid, quercetin and apigenin in Swertia mussotii Franch by capillary zone electrophoresis with running buffer modifier. Biomed. Chromatogr. 2015, 29, 402-409. [CrossRef]

96. Maher, H.M.; Al-Zoman, N.Z.; Al-Shehri, M.M.; Al-Showiman, H.; Al-Taweel, A.M.; Fawzy, G.A.; Perveen, S. Determination of Luteolin and Apigenin in Herbs by Capillary Electrophoresis with Diode Array Detection. Instrum. Sci. Technol. 2015, 43, 611-625. [CrossRef]

97. Wang, W.; Lin, P.; Ma, L.; Xu, K.; Lin, X. Separation and determination of flavonoids in three traditional Chinese medicines by capillary electrophoresis with amperometric detection. J. Sep. Sci. 2016, 39, 1357-1362. [CrossRef] 
98. Sereia, A.L.; Longhini, R.; Lopes, G.C.; de Mello, J.C.P. Capillary Electrophoresis as Tool for Diastereomeric Separation in a Trichilia catigua Fraction. Phytochem. Anal. 2017, 28, 144-150. [CrossRef]

99. Emara, S.; Masujima, T.; Zarad, W.; Mohamed, K.; Kamal, M.; Fouad, M.; EL-Bagary, R. Field-amplified sample stacking $\beta$-cyclodextrin modified capillary electrophoresis for quantitative determination of diastereomeric saponins. J. Chromatogr. Sci. 2014, 52, 1308-1316. [CrossRef]

100. Gufler, V.; Ngoc, H.N.; Stuppner, H.; Ganzera, M. Capillary electrophoresis as a fast and efficient alternative for the analysis of Urceola rosea leaf extracts. Fitoterapia 2018, 125, 1-5. [CrossRef]

101. Li, W.L.; Li, M.J.; Pan, Y.L.; Huang, B.K.; Chu, Q.C.; Ye, J.N. Study on electrochemical profiles of Valeriana medicinal plants by capillary electrophoresis. J. Anal. Chem. 2014, 69, 179-186. [CrossRef]

102. Uzaşçi, S.; Erim, F.B. Enhancement of native fluorescence intensity of berberine by (2-hydroxypropyl)- $\beta$-cyclodextrin in capillary electrophoresis coupled by laser-induced fluorescence detection: Application to quality control of medicinal plants. J. Chromatogr. A 2014, 1338, 184-187. [CrossRef]

103. Ma, D.; Yang, L.; Yan, B.; Sun, G. Capillary electrophoresis fingerprints combined with chemometric methods to evaluate the quality consistency and predict the antioxidant activity of Yinqiaojiedu tablet. J. Sep. Sci. 2017, 40, 1796-1804. [CrossRef]

104. Hancu, G.; Simon, B.; Rusu, A.; Mircia, E.; Gyéresi, Á. Principles of micellar electrokinetic capillary chromatography applied in pharmaceutical analysis. Adv. Pharm. Bull. 2013, 3, 1-8. [CrossRef] [PubMed]

105. Yang, H.; Ding, Y.; Gao, W.; Qi, L.W.; Cao, J.; Li, P. Efficient separation of tanshinones by polyvinylpyrrolidone-stabilized graphene-modified micellar electrokinetic chromatography. Electrophoresis 2015, 36, 2874-2880. [CrossRef]

106. Cao, J.; Li, P.; Yi, L. Ionic liquids coated multi-walled carbon nanotubes as a novel pseudostationary phase in electrokinetic chromatography. J. Chromatogr. A 2011, 1218, 9428-9434. [CrossRef] [PubMed]

107. Chang, Y.Q.; Tan, S.N.; Yong, J.W.H.; Ge, L. Surfactant-assisted pressurized liquid extraction for determination of flavonoids from Costus speciosus by micellar electrokinetic chromatography. J. Sep. Sci. 2011, 34, 462-468. [CrossRef] [PubMed]

108. Chang, Y.H.; Huang, C.W.; Fu, S.F.; Wu, M.Y.; Wu, T.; Lin, Y.W. Determination of salicylic acid using a magnetic iron oxide nanoparticle-based solid-phase extraction procedure followed by an online concentration technique through micellar electrokinetic capillary chromatography. J. Chromatogr. A 2017, 1479, 62-70. [CrossRef] [PubMed]

109. Matei, A.O.; Gatea, F.; Teodor, E.D.; Radu, G.L. Tannins analysis from different medicinal plants extracts using MALDI-TOF and MEKC. Chem. Pap. 2016, 70, 515-522. [CrossRef]

110. Huang, X.; Yi, L.; Gao, Z.; Li, H. Determination of Seven Active Ingredients in Three Plant Essential Oils by Using Micellar Electrokinetic Chromatography. Anal. Lett. 2012, 45, 2014-2025. [CrossRef]

111. Wei, M.; Chu, C.; Wang, S.; Yan, J. Quantitative analysis of sesquiterpenes and comparison of three Curcuma wenyujin herbal medicines by micro matrix solid phase dispersion coupled with MEEKC. Electrophoresis 2018, 39, 1119-1128. [CrossRef] [PubMed]

112. Fiori, J.; Leoni, A.; Fimognari, C.; Turrini, E.; Hrelia, P.; Mandrone, M.; Iannello, C.; Antognoni, F.; Poli, F.; Gotti, R. Determination of Phytomarkers in Pharmaceutical Preparations of Hemidesmus indicus Roots by Micellar Electrokinetic Chromatography and High-Performance Liquid Chromatography-Mass Spectrometry. Anal. Lett. 2014, 47, 2629-2642. [CrossRef]

113. Dresler, S.; Bogucka-Kocka, A.; Kováčik, J.; Kubrak, T.; Strzemski, M.; Wójciak-Kosior, M.; Rysiak, A.; Sowa, I. Separation and determination of coumarins including furanocoumarins using micellar electrokinetic capillary chromatography. Talanta 2018, 187, 120-124. [CrossRef]

114. Lao, K.M.; Han, D.Q.; Chen, X.J.; Zhao, J.; Wang, T.J.; Li, S. ping Simultaneous determination of seven hydrophilic bioactive compounds in water extract of Polygonum multiflorum using pressurized liquid extraction and short-end injection micellar electrokinetic chromatography. Chem. Cent. J. 2013, 7, 1-8. [CrossRef] [PubMed]

115. Stege, P.W.; Sombra, L.L.; Davicino, R.C.; Olsina, R.A. Analysis of nordihydroguaiaretic acid in Larrea divaricata Cav. extracts by micellar electrokinetic chromatography. Phytochem. Anal. 2011, 22, 74-79. [CrossRef]

116. Chen, S.; Sun, G.; Yang, L.; Zhang, J. Micellar electrokinetic chromatography fingerprinting combined with chemometrics as an efficient strategy for evaluating the quality consistency and predicting the antioxidant activity of Lianqiao baidu pills. J. Sep. Sci. 2017, 40, 2838-2848. [CrossRef]

117. Dobrecky, C.B.; Flor, S.A.; López, P.G.; Wagner, M.L.; Lucangioli, S.E. Development of a novel dual CD-MEKC system for the systematic flavonoid fingerprinting of Ligaria cuneifolia (R. et P.) Tiegh.—Loranthaceae-extracts. Electrophoresis 2017, 38, 1292-1300. [CrossRef]

118. Gomes, A.F.; Ganzera, M.; Schwaiger, S.; Stuppner, H.; Halabalaki, M.; Almeida, M.P.; Leite, M.F.; Amaral, J.G.; David, J.M Simultaneous determination of iridoids, phenylpropanoids and flavonoids in Lippia alba extracts by micellar electrokinetic capillary chromatography. Microchem. J. 2018, 138, 494-500. [CrossRef]

119. Głowacki, R.; Furmaniak, P.; Kubalczyk, P.; Borowczyk, K. Determination of Total Apigenin in Herbs by Micellar Electrokinetic Chromatography with UV Detection. J. Anal. Methods Chem. 2016, 2016. [CrossRef] [PubMed]

120. Gonda, S.; Nguyen, N.M.; Batta, G.; Gyémánt, G.; Máthé, C.; Vasas, G. Determination of phenylethanoid glycosides and iridoid glycosides from therapeutically used Plantago species by CE-MEKC. Electrophoresis 2013, 34, 2577-2584. [CrossRef] [PubMed]

121. Öztekin, N.; Başkan, S.; Evrim Kepekçi, S.; Erim, F.B.; Topçu, G. Isolation and analysis of bioactive diterpenoids in Salvia species (Salvia chionantha and Salvia kronenburgiii) by micellar electrokinetic capillary chromatography. J. Pharm. Biomed. Anal. 2010, 51, 439-442. [CrossRef] [PubMed] 
122. Cao, J.; Hu, J.; Wei, J.; Li, B.; Zhang, M.; Xiang, C.; Li, P. Optimization of micellar electrokinetic chromatography method for the simultaneous determination of seven hydrophilic and four lipophilic bioactive components in three salvia species. Molecules 2015, 20, 15304-15318. [CrossRef] [PubMed]

123. Ma, H.; Liu, T.; Li, J.; Ding, M.; Gao, X.M.; Chang, Y. xu The in-capillary-2,2-azinobis-(3-ethylbenzothiazoline-6-sulfonic acid)sweeping micellar electrokinetic chromatography-Diode array detector method for screening and quantifying trace natural antioxidants from Schisandra chinensis. J. Chromatogr. A 2019, 1593, 147-155. [CrossRef] [PubMed]

124. Riekkola, M.L.; Jussila, M.; Porras, S.P.; Valkó, I.E. Non-aqueous capillary electrophoresis. J. Chromatogr. A 2000, 892, 155-170. [CrossRef]

125. Hou, J.; Li, G.; Wei, Y.; Lu, H.; Jiang, C.; Zhou, X.; Meng, F.; Cao, J.; Liu, J. Analysis of five alkaloids using surfactant-coated multi-walled carbon nanotubes as the pseudostationary phase in nonaqueous capillary electrophoresis. J. Chromatogr. A 2014, 1343, 174-181. [CrossRef]

126. Yuan, B.; Zheng, C.; Teng, H.; You, T. Simultaneous determination of atropine, anisodamine, and scopolamine in plant extract by nonaqueous capillary electrophoresis coupled with electrochemiluminescence and electrochemistry dual detection. J. Chromatogr. A 2010, 1217, 171-174. [CrossRef]

127. Mistry, K.; Krull, I.; Grinberg, N. Capillary electrochromatography: An alternative to HPLC and CE. J. Sep. Sci. 2002, 25, 935-958. [CrossRef]

128. Svec, F. Recent developments in the field of monolithic stationary phases for capillary electrochromatography. J. Sep. Sci. 2005, 28, 729-745. [CrossRef]

129. de Jong, G. Milestones in the Development of Capillary Electromigration Techniques; Elsevier Inc.: Amsterdam, The Netherland, 2018; ISBN 9780128093757.

130. Viberg, P.; Spégel, P.; Carlstedt, J.; Jörntén-Karlsson, M.; Petersson, P. Continuous full filling capillary electrochromatography: Chromatographic performance and reproducibility. J. Chromatogr. A 2007, 1154, 386-389. [CrossRef] [PubMed]

131. Ping, G.; Schmitt-Kopplin, P.; Zhang, Y.; Baba, Y. Capillary electrochromatography and on-line concentration. Methods Mol. Biol. 2008, 384, 751-769. [CrossRef]

132. Yan, C.; Xue, Y.; Wang, Y. Capillary Electrochromatography; Elsevier Inc.: Amsterdam, The Netherland, 2018; ISBN 9780128093757.

133. Chen, Z.; Wang, J.; Chen, D.; Fan, G.; Wu, Y. Sodium desoxycholate-assisted capillary electrochromatography with methacrylate ester-based monolithic column on fast separation and determination of coumarin analogs in Angelica dahurica extract. Electrophoresis 2012, 33, 2884-2891. [CrossRef]

134. Wang, J.; Chen, D.; Chen, Z.; Fan, G.; Wu, Y. Fast separation and determination of coumarins in Fructus cnidii extracts by CEC using poly(butyl methacrylate-co-ethylene dimethacrylate-co-[2-(methacryloyloxy) ethyl] trimethylammonium chloride) monolithic columns. J. Sep. Sci. 2010, 33, 1099-1108. [CrossRef] [PubMed]

135. Chen, Q.; Li, N.; Zhang, W.; Chen, J.; Chen, Z. Simultaneous determination of vinblastine and its monomeric precursors vindoline and catharanthine in Catharanthus roseus by capillary electrophoresis-mass spectrometry. J. Sep. Sci. 2011, 34, $2885-2892$. [CrossRef] [PubMed]

136. Liu, Y.; Zhou, W.; Mao, Z.; Chen, Z. Analysis of Evodiae Fructus by capillary electrochromatography-mass spectrometry with methyl-vinylimidazole functionalized organic polymer monolilth as stationary phases. J. Chromatogr. A 2019, 1602, 474-480. [CrossRef] [PubMed]

137. Wang, Q.Y.; Dong, X.; Yang, J.; Zhen, X.T.; Ye, L.H.; Chu, C.; Wang, B.; Hu, Y.H.; Zheng, H.; Cao, J. Solid acids assisted matrix solid-phase dispersion microextraction of alkaloids by capillary electrophoresis coupled with quadrupole time-of-flight mass spectrometry. J. Sep. Sci. 2019, 42, 3579-3588. [CrossRef]

138. Zhang, Y.; Chen, Z. Nonaqueous CE ESI-IT-MS analysis of Amaryllidaceae alkaloids. J. Sep. Sci. 2013, 36, 1078-1084. [CrossRef]

139. Zhang, Y.; Chen, Z. Separation of isomeric bavachin and isobavachalcone in the Fructus Psoraleae by capillary electrophoresismass spectrometry. J. Sep. Sci. 2012, 35, 1644-1650. [CrossRef]

140. Posch, T.N.; Martin, N.; Pütz, M.; Huhn, C. Nonaqueous capillary electrophoresis-mass spectrometry: A versatile, straightforward tool for the analysis of alkaloids from psychoactive plant extracts. Electrophoresis 2012, 33, 1557-1566. [CrossRef]

141. Cheng, J.; Wang, L.; Liu, W.; Chen, D.D.Y. Quantitative Nonaqueous Capillary Electrophoresis-Mass Spectrometry Method for Determining Active Ingredients in Plant Extracts. Anal. Chem. 2017, 89, 1411-1415. [CrossRef] [PubMed]

142. Chen, Q.; Zhang, J.; Zhang, W.; Chen, Z. Analysis of active alkaloids in the Menispermaceae family by nonaqueous capillary electrophoresis-ion trap mass spectrometry. J. Sep. Sci. 2013, 36, 341-349. [CrossRef] [PubMed] 